\title{
Design, fabrication and characterization of drug delivery systems based on lab-on-a-chip technology
}

\author{
Nam-Trung Nguyen ${ }^{a^{*}}$, Seyed Ali Mousavi Shaegh ${ }^{b}$, Navid Kashaninejad ${ }^{c}$, Dinh-Tuan \\ Phan $^{\mathrm{c}}$ \\ a Queensland Micro and Nanotechnology Centre, Griffith University, Brisbane, 4111, \\ Australia \\ b SIMTech, Singapore Institute for Manufacturing Technoly, Singapore 638075, Singapore \\ c School of Mechanical and Aerospace Engineering, Nanyang Technological University, 50 \\ Nanyang Avenue, Singapore, 639798, Singapore
}

\begin{abstract}
Lab-on-a-chip technology is an emerging field evolving from the recent advances of micro- and nanotechnologies. The technology allows the integration of various components into a single microdevice. Microfluidics, the science and engineering of fluid flow in microscale, is the enabling underlying concept for lab-on-a-chip technology. The present paper reviews the design, fabrication and characterization of drug delivery systems based on this amazing technology. The systems are categorized and discussed according to the scales at which the drug is administered. Starting with the fundamentals on scaling laws of mass transfer and basic fabrication techniques, the paper reviews and discusses drug delivery devices for cellular, tissue and organism levels. At the cellular level, a concentration gradient generator integrated with a cell culture platform is the main drug delivery scheme of interest. At the tissue level, the synthesis of smart particles as drug carriers using lab-on-a-chip technology is the main focus of recent developments. At the organism level, microneedles and implantable devices with fluid-handling components are the main drug delivery systems. For drug delivery to a small organism that can fit into a microchip, devices similar to those of cellular level can be used.
\end{abstract}

\section{Contents}

1. Introduction

2. Fundamentals and basic fabrication technologies

2.1. Scaling law

2.2. Micromachining technologies

3. Design considerations for drug delivery systems

3.1. Drug delivery on cellular level

3.1.1. Microfluidic platforms 
3.1.2. Gradient generators for cell-based drug investigations

3.2. Drug delivery on tissue level

3.2.1. Smart particles as drug carries

3.2.2. Production of smart particles using microfluidic technology

3.3. Drug delivery on the organism level

3.3.1. Micro needles

3.3.2. Living systems on a chip

3.3.3. Implanted microfluidic drug delivery devices

4. Conclusions

References 


\section{Introduction}

In this paper, drug delivery is understood in a broad sense as the method of administering a therapeutic compound to a biological system ranging from cells to living organisms. Drug delivery systems control the various processes of release, absorption, distribution and elimination of drug. Conventional delivery methods administer drug through the mouth, the skin, transmucosal areas, inhalation or injection. Since many new drugs such as peptides, proteins and DNA-based therapeutics are susceptible to enzymatic degradation, the long pathway of conventional drug delivery may make the drug ineffective [1]. Recent advances in micro- and nanotechnologies may shorten the delivery pathway and makes it more targeted. Miniaturisation allows the integration of components of a drug delivery system into a single chip, the lab on a chip. The lab-on-a-chip (LOC) platform is based on a broader technology called microfluidics, the science and engineering of fluid flow in microscale. LOC technology impacts on drug delivery technology in many ways, from the synthesis of drug carriers, to screening, and to the delivery system itself.

One of the current challenges of drug delivery is effective and targeted administration. To warrant a sustainable release, drug formulations are protected and transported by carriers in the form of liposomes, biodegradable particles. LOC platform and microfluidic technology would allow a reliable synthesis of these drug carriers. Another challenge of drug delivery is the burst release of conventional delivery methods that reduces the efficacy of the therapy and increases the risk of side effects. A drug delivery system based on LOC technology is sophisticated enough to administer drug continuously at a controllable rate. As a future trend, drug synthesis and delivery system are closely linked. In this case, LOC may allow the integration of both synthesis and delivery on a single device. 
Besides the above mentioned improvement in efficacy, the small size and the compact integration of LOC-based drug delivery bring further advantages such as reduced pain, ease of use, portability, improved safety and no need of trained personnel. Some traditional delivery methods also benefit from microtechnology. For instance, injection using microneedles or needle-free injection would reduce the pain and hazard caused by conventional injections.

As mentioned at the start, this paper looks at drug delivery from a different perspective than just the narrow view of delivery as administration of a drug to a target. The objective of this paper is the review and discussion of the impact of micro- nanotechnology and LOC technology on the delivery of drugs to different levels of a biological system: cell, tissue and organism. The design, fabrication and characterization of examples from published literature are reviewed and discussed accordingly. Following, scaling law and basic fabrication technologies first form the foundation for the subsequent discussions on design considerations of drug delivery systems. Next, devices for drug delivery at cellular level with applications in drug testing and drug screening are discussed. At the tissue level, instead of discussing the delivery devices, the paper focuses on the synthesis of drug carriers that benefit from LOC technology. And finally at organism level, the paper focuses on the development of microneedles, organ-on-a-chip platform and implantable drug delivery devices.

\section{Fundamentals and basic fabrication technologies}

\subsection{Scaling law}

Drug delivery means controlling mass transport at microscale. Figure 1 shows the length scales of typical biological objects ranging from a protein molecule to a complex living organism such as human. The basic scaling law is the square-cube law indicating that surface-based phenomena become more significant than volume-based phenomena as the size decreases. The main consequence of this scaling law on drug delivery is that flow in microscale is laminar because 
viscous friction dominates of inertia. As convective transport and mixing become more difficult in microscale, mass transport relies mainly on molecular diffusion. Since the size of cells and drug compounds are on the order of micrometers and ten of nanometers respectively, diffusion is the main mode of mass transport for drug to reach cells. Thus, drug delivery is best controlled with nanofluidic and microfluidic tools that are offered by LOC technology. Since most drug delivery systems are handled by human hand, the design of such system should accommodate to both microscale mass transport and mesoscale handling.

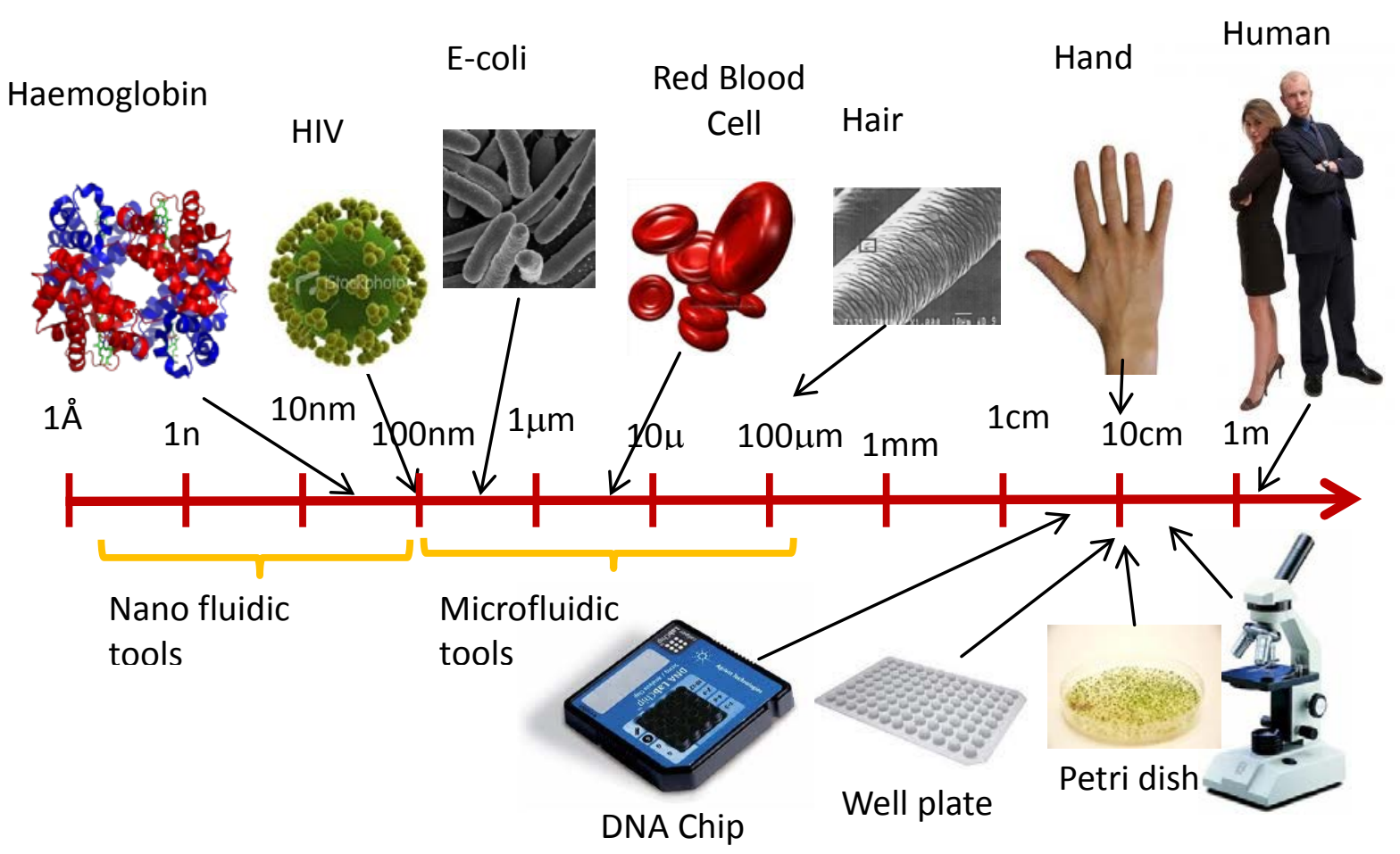

Fig. 1. Lab-on-a-chip technologies as tools at molecular and cellular scale.

\subsection{Micromachining technologies}

Micromachining technologies evolved from the technologies of microelectronics such as deposition, etching and pattern transfer of material layers on a substrate. The basic materials used in micromachining are silicon, glass, metals and polymers. Silicon is the basic material of microelectronics. Silicon shows good mechanical properties suitable for making components of 
drug delivery systems such as microneedles. Glass is another common material which can be micromachined by lithography and etching. Silicon can be bonded to glass using anodic bonding to form complex system with microchannels. Metals can also be used to make components of a drug delivery system. Common techniques for deposition of metals are evaporation, sputtering and electroplating. For large-scale production of microdevices, polymer is an ideal and economical candidate. Polymeric devices are fabricated by injection molding, hot embossing or stereolithography.

The first key micromachining technique is deposition. A thin film of material can be deposited on a substrate by physical deposition or chemical deposition. In physical deposition, materials are removed from a target by evaporation or ion bombardment. Evaporation can be achieved by heat or electron beam. The corresponding techniques are called thermal evaporation and e-beam evaporation, respectively. Deposition using ion bombardment is called sputtering. Chemical deposition techniques include chemical vapour deposition (CVD) and oxidation. In CVD, reaction between gaseous reactants leaves a thin film of solid product on the substrate. Reaction with oxygen or water vapour can be used for growing an oxide layer on a substrate.

The second key micromachining technique is etching. Etching techniques are categorized as wet etching and dry etching. In wet etching, the material is dissolved in a chemical solution. In dry etching, the material is attacked by reactive ions or a gaseous etchant. To make highaspect-ratio structures, deep reactive ion etching (DRIE) is often used. This technique alternates reactive ion etching and deposition of a protective polymer layer to gain a deep ad straight etch profile.

Photolithography is commonly used for transferring a pattern from the mask into a photoresist by selective exposure to light. After developing, the photoresist layer is used to transfer the pattern to a material layer through either deposition or etching. Since 
photolithography is limited by the wave length of the light used for exposure, finer structures in the nanometer scale require writing techniques such as electron beam lithography and ion beam lithography.

A recent pattern transfer technique called soft lithography refers to a family of techniques using elastomeric stamps and molds. Soft lithography was first used by Whiteside's group at Harvard for making microfluidic devices. Polydimethylsiloxane (PDMS) is a widely used material in soft lithography. A typical process for making PDMS microfluidic devices starts with the fabrication of a master using conventional micromachining such as DRIE of silicon or lithography of a thick-film resist such as SU-8. Next, the master is silanized to prevent sticking of PDMS. The mixture or PDMS precursor and curing agent are the poured over the mold. The device is subsequently cured under vacuum and elevated temperature before being removed from the master. Components for drug delivery systems based on LOC technology discussed in the subsequent sections are typically fabricated by the micromachining technologies mentioned above.

\section{Design considerations for drug delivery systems}

\subsection{Drug delivery at cellular level}

\subsubsection{Microfluidic platforms}

Fig. 3 shows the different stages of drug delivery. The method of drug delivery is of great importance because all administered drugs into the body should eventually reach the site of interest and taken up by the target cells to make their bioactivity effective [1].

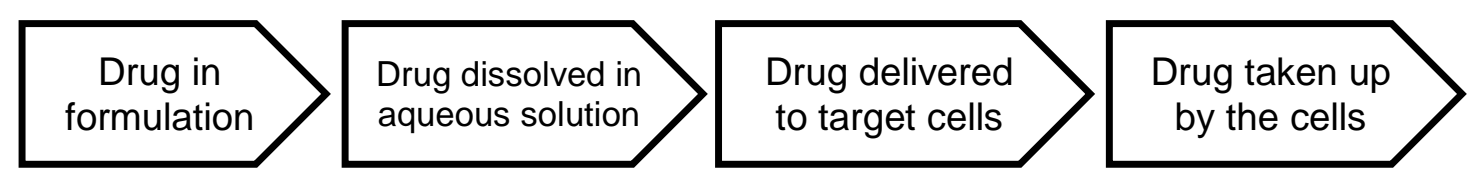

Fig. 2. Dissolvable drug molecules in different stages. Reproduced with permission from [1]. 
Cellular-level drug delivery methods are generally used for the study of cell-based drug screening and testing. Microtechnologies including microfabrication and microfluidics can provide devices with high spatiotemporal precision and to mimic in vivo microenvironments for drug screening [2-6] and drug discovery [7-9]. Using this technology, cell responses to mechanical and biochemical stimuli can be studied in a more physiologically appropriate environment $[4,10]$. Microfluidic-based cell culture platforms have been widely used for testing of preclinical toxicity [11-13] as well as concentration-dependent cellular response to drug conditions $[14,15]$. These devices are able to generate many controllable profiles of drug conditions for administration to a number of cells in a single microfluidic channel [16]. Consequently, microfluidic gradient generation devices can be exploited to study the effect of different biomolecule gradients on a particular biological cell response [16].

Compared to traditional methods for generating a concentration gradient such as Transwell assay and Dunn chambers, microfluidic-based gradient generation have unique characteristics including (i) reduced empirical operating expenses, (ii) high resolution, controllable and flexible drug concentration, (iii) ability of real-time observation of cellular response to administered concentration gradients; and (iv) high-throughput testing [2, 16, 17]. Such gradient generators can use either pure time-evolving diffusion through a microchannel or a membrane to dilute a chemical solute, or laminated parallel streams and subsequent diffusive mixing between the streams. The next section focuses on reviewing cell-based microfluidic gradient generators for investigations related to drug testing.

\subsubsection{Gradient generators for cell-based drug testing}

3.1.2.1 Time-evolving gradient generators. Microfluidic gradient generation devices are generally classified as time-evolving and steady-state gradient generators [16]. Time-evolving 
gradients generators basically consist of two reservoirs or compartments with high and low concentration of one or more reagents of interest. The compartments are connected by a bridge such as a channel $[18,19]$ or a valve [20]. Cells are cultured inside the bridging channel [18] or the compartment [20]. Fig. 3 shows a typical one-dimensional (1-D) concentration gradient between a source and a sink in a static configuration merely using diffusive transport. Abhyankar et al. [18] utilized a sink-source flow-free gradient generator to study neutrophil chemotaxis in response to a gradient profile using $10 \mu \mathrm{l}$ of reagents for 24 hours. The large volume of the sink improves stability of the established gradient. There is no convective flow leading to a shear-free environment for the cell culture. Since the volume of the chamber is limited, this method is suitable for fast-responding cells such as neutrophils or bacteria.

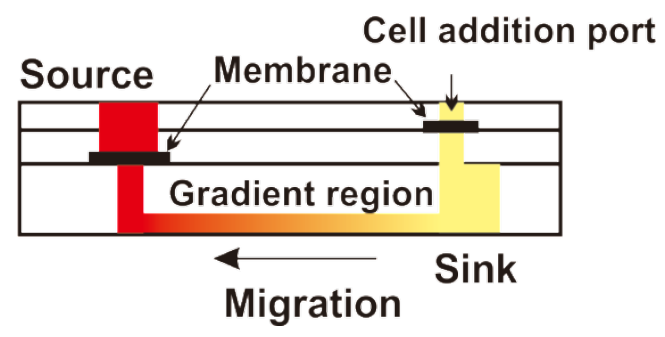

Fig. 3. Side view of a diffusion-based gradient generator. A chemical gradient is created along the $x$-direction of the channel. Cells are added to the system by putting them on the membrane in the cell addition port. Some added cells can pass through the membrane and into the sink reservoir, and then migrate into the source. Reproduced after [18].

3.1.2.2 Steady-state gradient generators. Steady-state gradient generators using continuous laminar flows are able to produce stable concentration gradients for long-term cell investigations. Fig. 4 shows multiple chemically different laminar streams in a microchannel. A concentration gradient is produced by controlled diffusive mixing of streams at the interfaces of the parallel streams [21]. This method attracts a huge attention by the research community because of the flexibility in creating and maintaining various gradient shapes for a period of time [16]. 

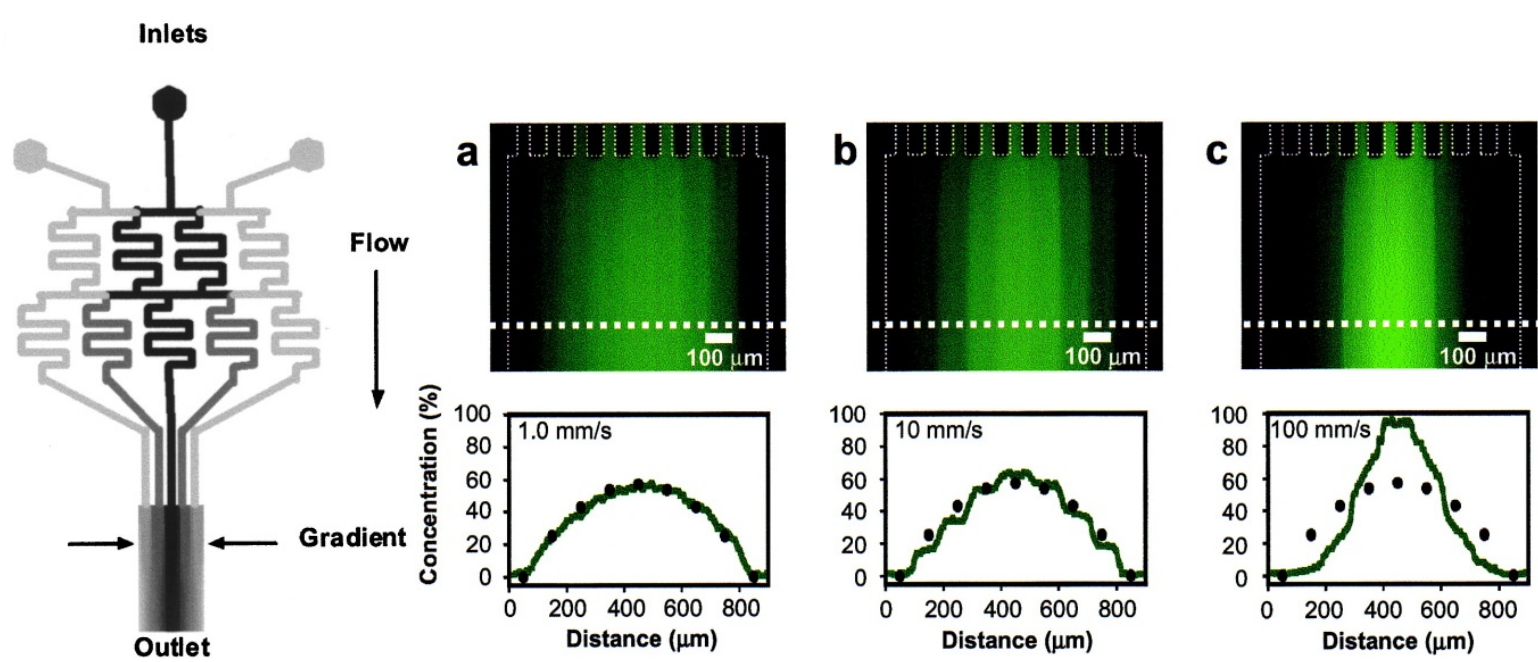

Fig. 4. (Left) A schematic of a tree-like steady-state gradient generator and (right) fluorescence micrographs of solution gradient of FITC (fluorescein isothiocynate) at the outlet channel region shown at flow speeds of $1 \mathrm{~mm} / \mathrm{s}$ (a), $10 \mathrm{~mm} / \mathrm{s}$ (b), and $100 \mathrm{~mm} / \mathrm{s}$ (c). Reprinted with permission from [21].

The most common designs of this concept are tree-like gradient generators (TLGGs) [21, 22]. Using the TLGG design, various microfluidic cell culture platforms for cell-drug responses have been successfully designed and characterized. The devices were used for applications such as high content screening of drug-induced apoptosis in human liver carcinoma (HepG2) cells [23] (Fig. 5), sensitivity to chemotherapy of breast cancer cells [15], analysis of lung cancer chemotherapy resistance [24] and studying the roles of $\mathrm{As}_{2} \mathrm{O}_{3}$ and buthionine sulfoximine (BSO) in mediating intracellular levels of reduced glutathione (GSH) and reactive oxygen species (ROS) in MCF-7 cells [25].

Gradients can be produced in TLGGs by adding more inlets and arranging the upstream mixers for controlling the orthogonal diffusion of chemical reagents between adjacently flowing streams. Sugiura et al. [26] reconfigured the inlets and the upstream mixers to make a concentration generator with a wide concentration range of up to 6 orders of magnitude for drug dose response assay of paclitaxel on HeLa cells. Irimia et al. [27] developed a Universal gradient generator using the T-sensor concept to create gradient profiles of exponential, $5^{\text {th }}$ order 
polynomial, cubic root and error functions. Gradient profiles were produced in a channel by adjusting the location of built-in weirs as dividers. This gradient generator has less dead volume as compared to TLGGs. In case of using this gradient generator for drug-cell studies, a smaller amount of possibly expensive compounds is required.

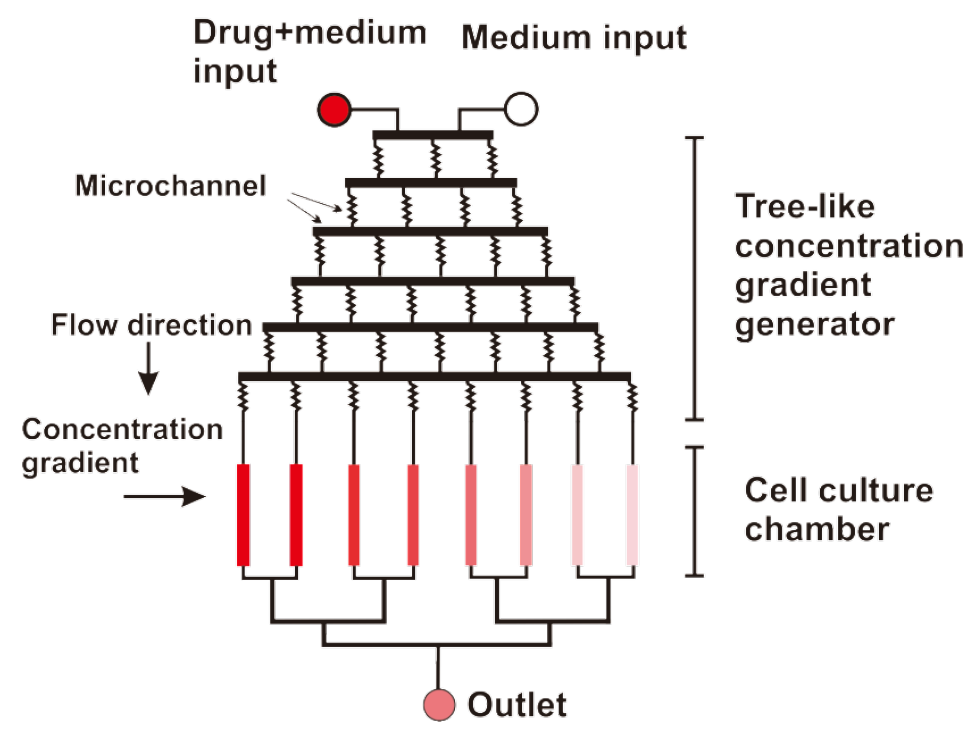

Fig. 5. Details of the single structure unit showing an upstream concentration gradient generator and downstream cell culture chambers. The device consists of eight uniform structure units. Each unit is connected by a common reservoir in the centre of device. Reproduced after [23].

Since convective laminar flows are generally used for steady-state gradient generators, flow-induced shear stress over the cells cannot be avoided $[2,16]$. Shear stress can affect the cellular behavior through asymmetric mass transport to the cell [28]. Also, it can cause experimental preference with bias on the direction of cell migration [29]. In addition, the convective flows can flush away potentially important cell-secreted factors including autocrine and paracrine signals $[16,30]$. In the case of studying chemotaxis of nano adherent cells in a flow-based gradient generator, cells may be washed away completely by the flow [30]. In addition, in the above mentioned microfluidic-based cell culture and gradient generators cells are usually seeded on top of a two-dimensional (2-D) substrate. Currently, it is generally agreed that many important biological processes may be ignored in 2-D cell culture models [31]. 
In order to address the above mentioned situations and to generate a mere steady-state diffusive gradient, three-dimensional (3D) gels or matrixes are used as alternative approaches [31]. Shin et al. [32] has recently developed a robust microfluidic assay to facilitate the interaction of cells in a 3-D extracellular matrix using hydrogels, Fig. 6. This protocol can be used for the investigation on the effect of the gradient of growth factors introduced in media or secreted by co-cultured tumor cells [32].
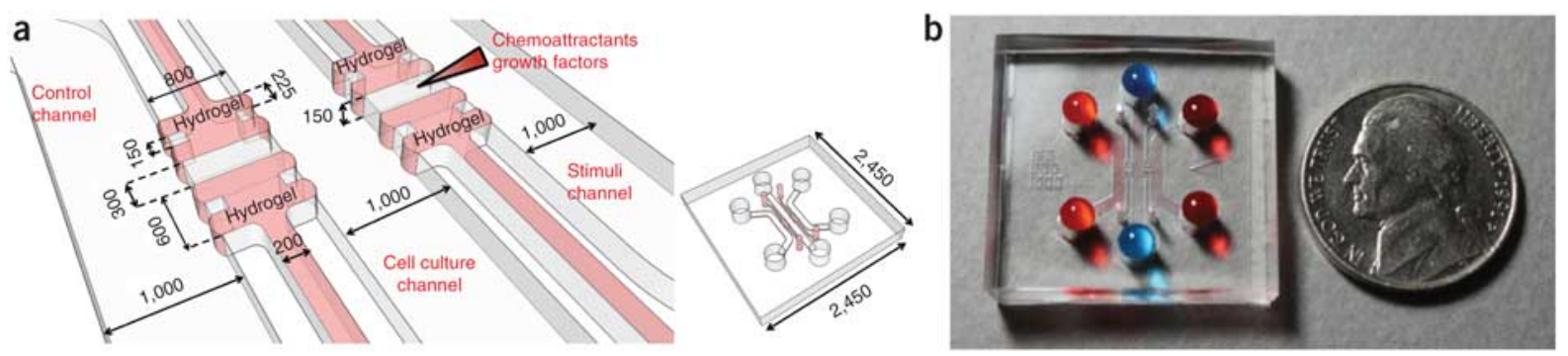

Fig. 6. A microfluidic cell culture assay: (a) Schematic; (b) Fabricated device. The device incorporates hydrogel and colored liquids in the side channels (red) and central channel (blue). All scale are in $\mu \mathrm{m}$. Reprinted with permission from [32].

In general, the steady-state microfluidic gradient generators only allow orthogonal diffusive mixing at the interface of two convective streams in a channel where a 1-D gradient profile is produced. In this way, diffusive mixing is highly dependent on the hydrodynamic conditions of laminar streams. Atencia et al. [30] decoupled diffusive mixing in a main chamber from convective delivery streams without the need for a membrane or gels using a microfluidic palette. As shown in Fig. 7, this gradient generator is mainly comprised of a main chamber, a palette, for diffusion of multiple solutes that are delivered to the chamber through lateral convective streams without any shear stress. Overlapping gradients of many solutes can be generated with different spatial locations. A dynamic control over the gradients can be achieved with a shorter time as compared to gradient generators using membranes or gels [30]. However, this gradient generator is able to produce a convection-free concentration gradient of multiple solutes for cell-cell signaling studies and investigations on cellular responses to drugs and 
biological chemicals. The drawback of this device is the exposure to ambient environment during cell loading to the chamber.

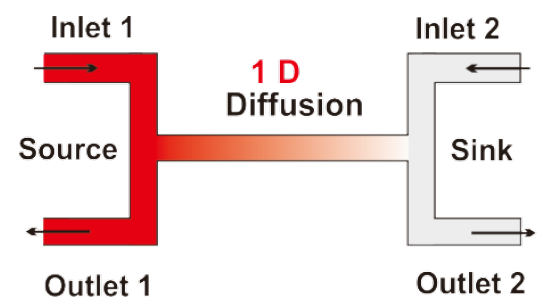

(a)

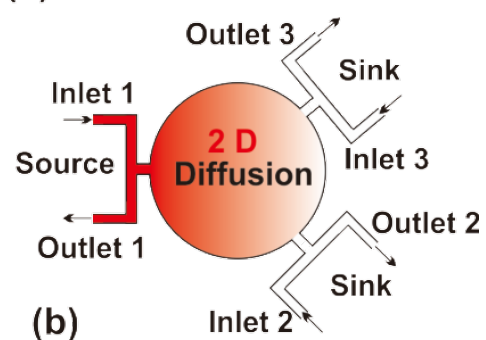

Fig. 7. (a) A 1-D convective unit for gradient generation along the channel. Diffusion occurs at the interface of the convective channel and the diffusion channel by matching the flow rates at inlet 1 and outlet 1; (b) A 2-D gradient generator using the same concept illustrated at (a). Reproduced after [30].

3.1.2.3 High-throughput combinatorial gradient generators. The aforementioned microfluidic cell-based gradient generators are mainly utilized for dilution of a single drug compound using a buffer solution for dose-response experiments. It is clear that cellular responses to some combinations of drugs or chemical compounds can be significantly different from responses to individual compounds [33]. Currently, it is well known that a balanced multi-component therapy might be more efficacious than a single component therapy for a specific case [34]. In addition, studies on chemotherapy treatment of HIV showed that the combinatorial effect of two or more drugs can enhance the treatment [35]. For drug screening and optimization processes, various concentrations of combinatorial mixtures of different drug compounds are required [36, 37]. Consequently, an interest in developing microfluidic approaches for combinatorial and highthroughput drug discovery has been increased. It is worthy to mention that the term combinatorial refers to experiments in which groups or elements of materials or different components of a recipe including solvents, additives, etc. are combined [38]. 
Lee et al. [36, 37] used simplex-centroid concept to design and fabricate a network-based combinatorial dilution device, Figure 8. The three-layer device is able to provide seven combinations (ABC/D, AB/D, BC/D, $\mathrm{AC} / \mathrm{D}, \mathrm{A} / \mathrm{D}, \mathrm{B} / \mathrm{D}$, and $\mathrm{C} / \mathrm{D})$ of three additive samples (A, B, and C) into a buffer solution (D). For cell-based drug testing, this device should be integrated with cell culture chambers.

Liu et al. [39] developed a monolithic microfluidic network using surface micromachining of parylene $\mathrm{C}$ (poly(chloro-p-xylylene)) to address the alignment difficulties between the multiple layers. The device was made of one control inlet and three additive inlets for seven combinatorial mixing, mixing channels and eight cell-culture chambers for cell-based screening as shown in Fig. 9.

Schudel et al. [40] fabricated an $4 \times 4$ array of microfluidic wells for bio sensing. Each well was made of two 200-picoliter compartments to contain a photonic crystal biosensor for onchip and in-situ detection of (bio-) molecular binding events. A proof-of-concept of this device was used for demonstrating discrete mixing and on-chip capabilities of protein/antibody binding assays. 


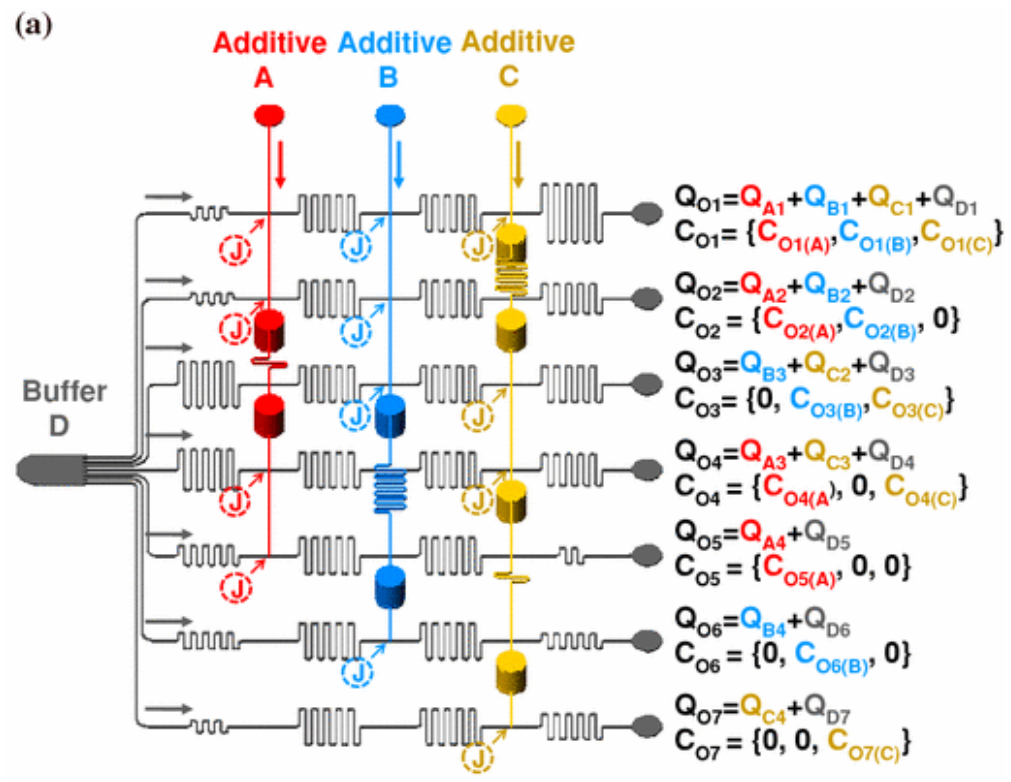

(b) Cross-sectional view of a-a'

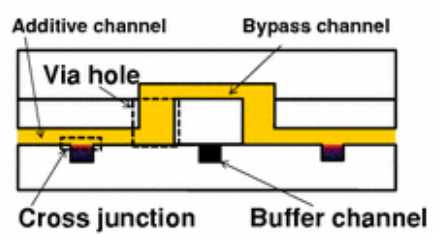

(c) The simplex centroid configuration

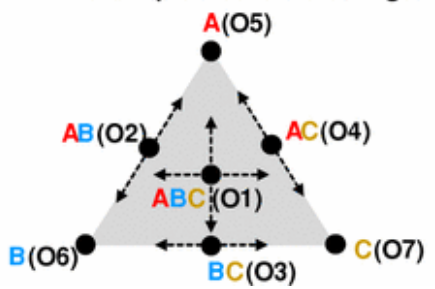

Fig. 8. Combinatorial dilution device: (a) The schematic layout of a device generating seven combinatorial dilution mixings of three additives; (b) The cross sectional view of the three-layer microfluidic network; (c) The simplex-centroid configuration comprising of seven combinations ( $A B C / D, A B / D, B C / D, A C / D, A / D$,

$\mathrm{B} / \mathrm{D}$, and $\mathrm{C} / \mathrm{D}$ ) for three additives (A, B, and C) with a buffer solution (D) in a combinatorial approach.

Reprinted with permission from [37].
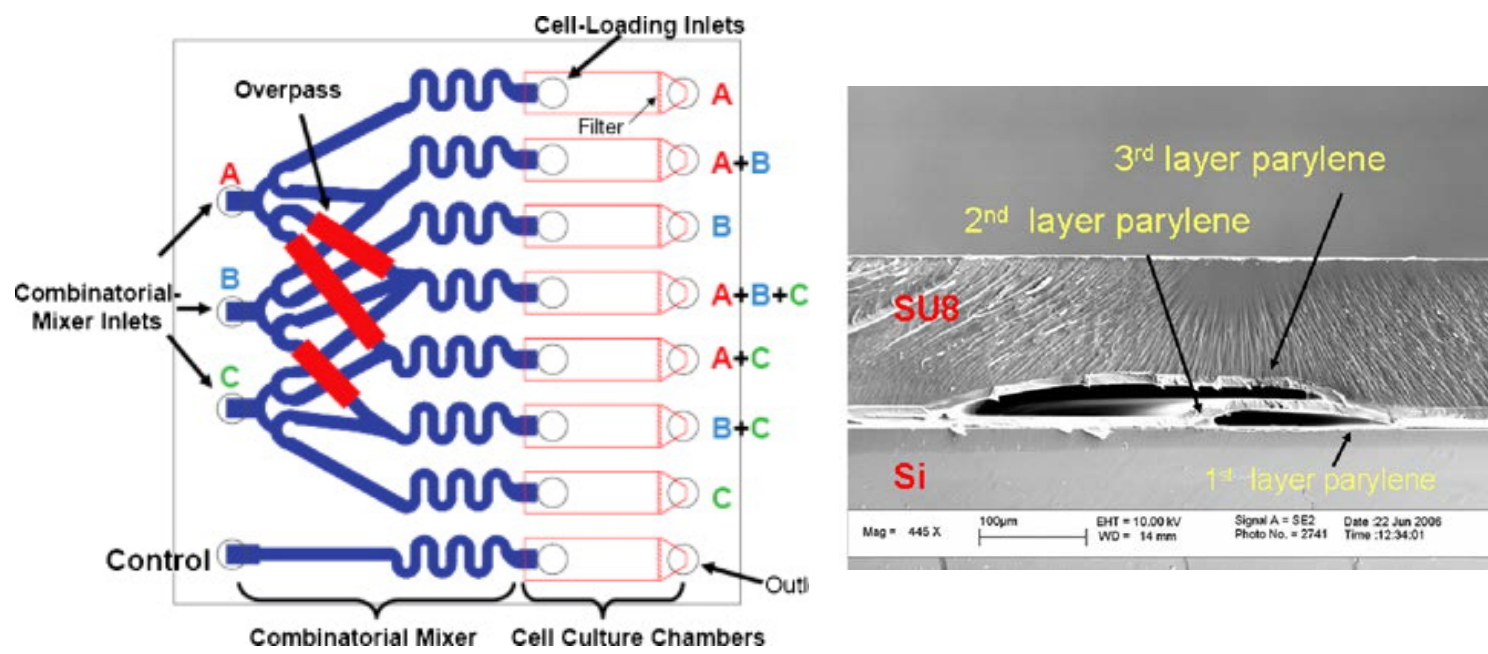

Fig. 9. Layout of the combinatorial device design (left). Three separate inlets produced seven different combinations. Combinatorial mixing is carried out through microfluidic overpass structures. SEM image of the cross-section of the microfluidic overpass (right). Cells can be grown inside the culture chambers. The chip has a dimension of $1 \mathrm{~cm} \times 1 \mathrm{~cm}$. Reprinted with permission from [39]. 
Jang et al. [41] integrated an array of $8 \times 8$ and $10 \times 10$ microwells with a 2-D microfluidic combinatorial gradient generator using three layers of PDMS. Gradient generator was comprised of a TLGG and a new microfluidic active injection system (MAI). Pneumatically-actuated including normally closed and normally open control valves and channels were made in PDMS. As shown in Fig. 10, in order to make a 2-D combinatorial dilution, solution $\mathrm{C}$ was injected to cylindrical microwells to pre-fill them. Then, ten graded mixtures coming from 1-D TLGG with two input solutions of A and B were stored separately in intermediate reservoirs. Using MAI system, ten graded mixtures stored in reservoirs were injected into separate columns of 21-nL pre-filled cylindrical microwells as test chambers. Contents within a microwell were mixed with pre-filled solution $\mathrm{C}$ through convective flow and diffusion. Therefore, the concentration of the incoming solution was increased in the microwell and decreased in the stream leaving the microwell. Cells can be loaded to microwells through the third solution (solution C) which isolate the cells from surrounding environment during the cell loading process.

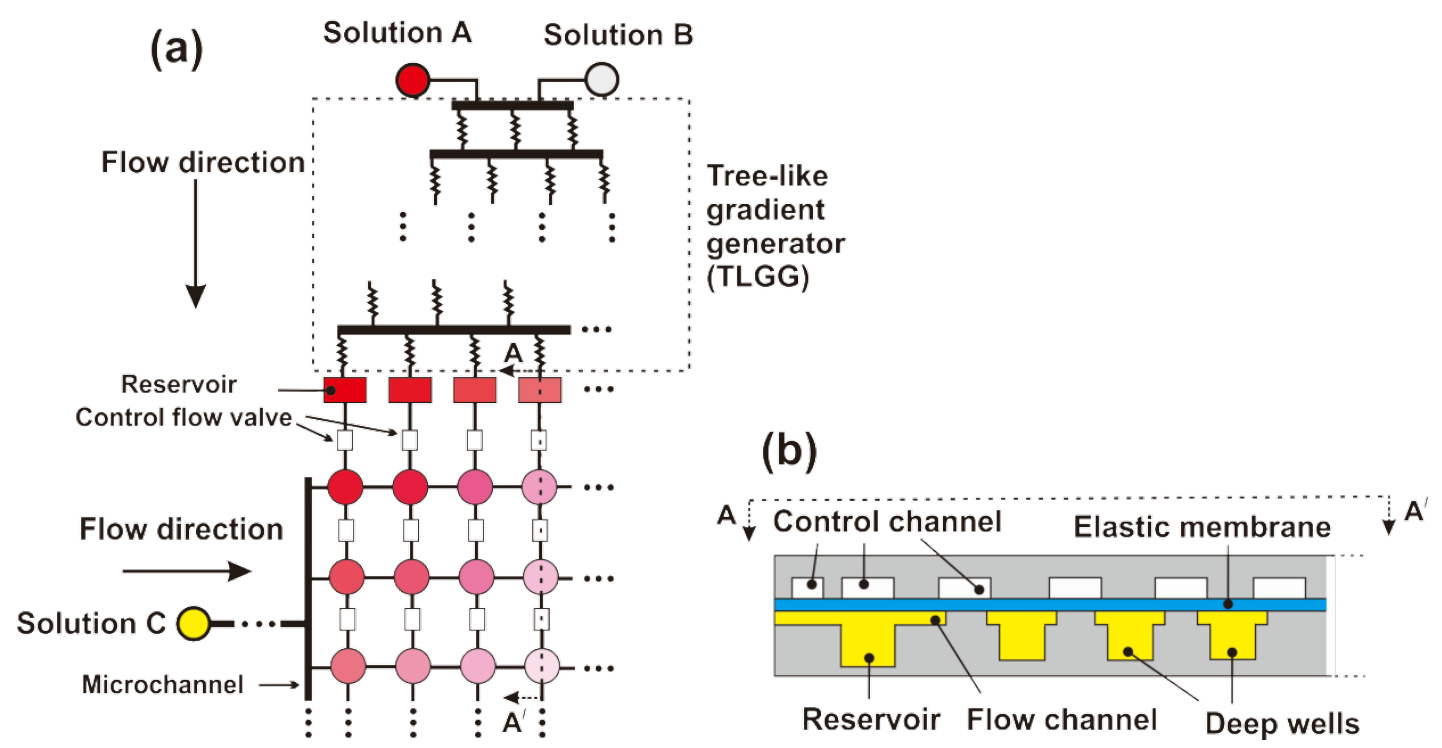

Fig. 10. Design and operation of the 2-D microfluidic combinatorial dilution device: (a) A tree-like gradient generator (TLGG) mixes two solutions inside reservoirs. Circular zones refer to an array of $10 \times 10$ microwells which are pre-filled with a third input solution $C$ flowing from left connected by flow channels and controlled by control channels (not shown); (b) cross-section view of the device along the dashed line $\mathrm{AA}^{\prime}$ in (a) showing reservoir, deep microwells, control channels, and a thin membrane for the microfluidic active injection (MAI) system. Reproduced after [41]. 


\subsection{Drug delivery at tissue level}

The development of the microfluidic technology led to a paradigm shift in the drug delivery [4244] as well as drug discovery applications [9, 45-47]. The unique features of microfluidic devices make them excellent candidates for the treatment of diseases, where controlled and/or targeted (site-specific) delivery of the drug is vital. For efficient drug delivery and minimizing the drug toxicity, the administered dose of the drug should be maintained within a certain level, the therapeutic index. Furthermore, by utilizing smart micro/nanoparticles and devices, an optimal level of drug can be administered to the affected sites [48]. This approach of drug administration is crucial to cure many abnormalities such as cancerous tissues as well as diabetes and brain diseases. Investigating the functionality of drug delivery on multicellular interactions at the mesoscopic level, i.e. on a specific tissue site, is of great significance from both pharmacokinetics and pharmacodynamics points of view. On the tissue level, microfluidics technology is closely related to tissue engineering [49] and regenerative medicine [50]. Additionally, in vitro assays of drug pharmacology on the engineered tissue-on-a-chip samples resemble more realistically the in vivo behaviour of the drug. The summary of the applications of microfluidics on both in vitro and in vivo drug deliveries is presented in Table 1. Nevertheless, there are still many obstacles needed to be overcome to fully replace in vitro integrated wholeorganism-on-a-chip experimental scaffolds with the time consuming, expensive and sometimes misleading in vivo animal testing [47].

The focus of this section is the implementation of microfluidic technology at in vivo level with special emphasis given to the fabrication and characterization of smart particles as the drug carriers. The state-of-the-art advances in the development of the in vitro microfluidics-based biomimetic tissues on a chip were presented in the recent reviews [51, 52]. 
Table 1. Comparison of different LOC drug delivery techniques on tissue level

\begin{tabular}{|c|c|c|}
\hline Study type & Delivery technique & Reference \\
\hline \multirow{3}{*}{$\begin{array}{c}\text { In vivo } \\
\text { (pharmaco-dynamics) }\end{array}$} & 1) Particulate drug delivery & {$[53]$} \\
\hline & 2) Microneedles & {$[54]$} \\
\hline & $\begin{array}{l}\text { 3) Implantable therapeutic } \\
\text { microchips (pharmacy-on-a-chip) }\end{array}$ & {$[44,55-57]$} \\
\hline $\begin{array}{c}\text { In vitro } \\
\text { (pharmaco-kinetics) }\end{array}$ & $\begin{array}{l}\text { 1) Brain-on-a-chip } \\
\text { 2) Heart-on-a-chip } \\
\text { 3) Liver-on-a-chip } \\
\text { 4) Lung-on-a-chip } \\
\text { 5) Kidney-on-a-chip } \\
\text { 6) Spleen-on-a-chip } \\
\text { 7) Intestine-on-a-chip } \\
\text { 8) Gut-on-a-chip } \\
\text { 9) Cornea-on-a-chip } \\
\text { 10) Blood vessel-on-a-chip } \\
\text { 11) Muscle-on-a-chip } \\
\text { 12) Bone marrow-on-a-chip } \\
\text { 13) Tumor-on-a-chip }\end{array}$ & $\begin{array}{l}{[58,59]} \\
{[60]} \\
{[13,61-64]} \\
{[3,65,66]} \\
{[67,68]} \\
{[51]} \\
{[51,69]} \\
{[70,71]} \\
{[60]} \\
{[72-79]} \\
{[80]} \\
{[81]} \\
{[60,82]}\end{array}$ \\
\hline
\end{tabular}

\subsubsection{Smart particles as drug carriers}

For in-vivo drug delivery applications, drug carriers capable of smart delivery of the drug to the intended unhealthy tissue and releasing the required drug dose accordingly, termed as smart particles, have attracted significant attention from the research community [48, 83-87]. These smart particles can be classified into biocapsules [88, 89], microparticles [90], and nanoparticles [91], as shown in Fig. 11. 


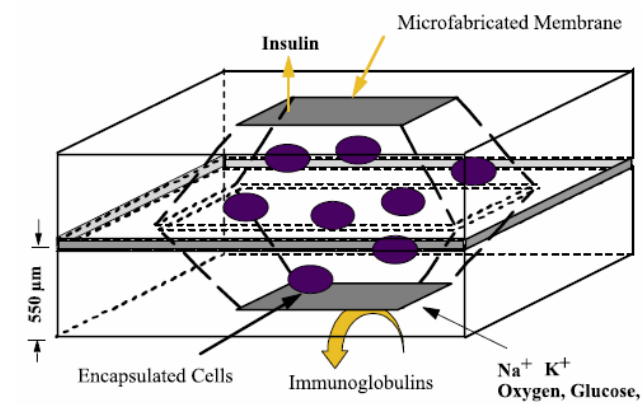

(a)

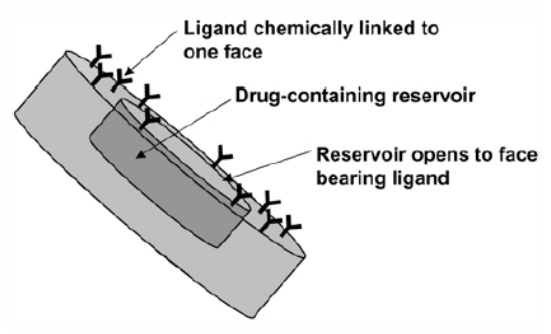

(b)

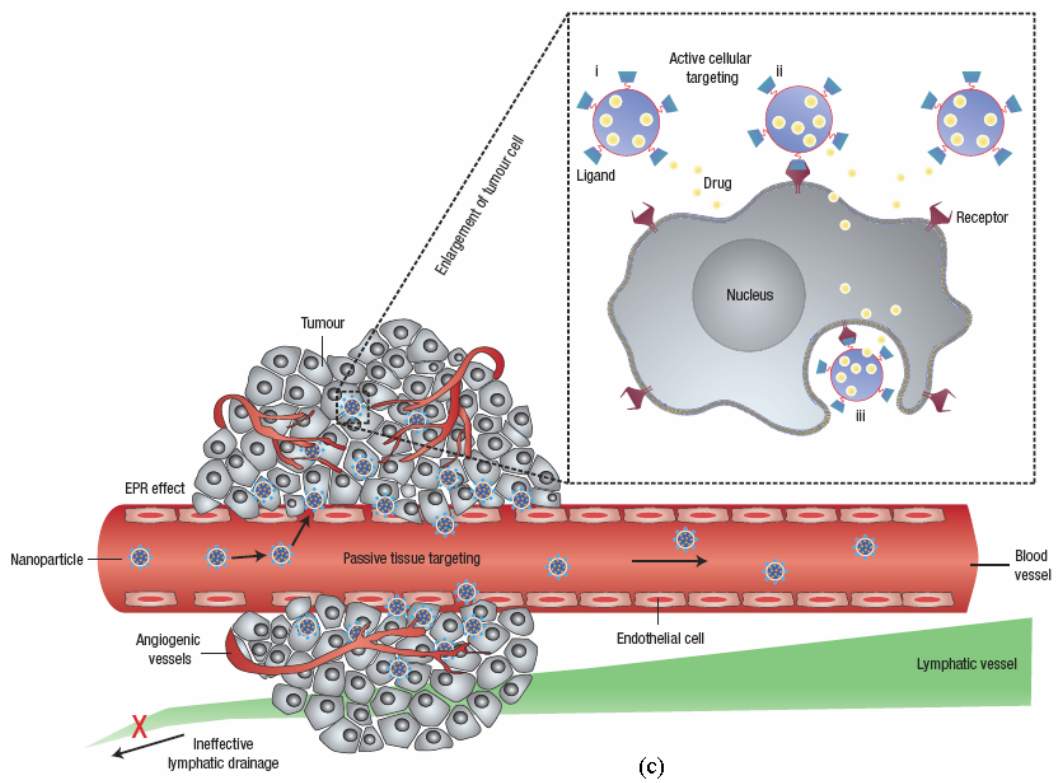

Fig. 11. Types of smart particles: (a) implantable biocapsule [92]. (b) Microparticle [93]. (c) Nanoparticle. Reprinted with permission from [91].

\subsubsection{Biocapsules. Transplanted and/or microengineered tissues may be identified as a foreign} objects and rejected by the immune system. Encapsulating these artificial tissues into a biodegradable and semi-permeable microcapsule is an effective method of immunoisolation. Incorporating porous silicon with controlled nanopores as the selective-permeable membrane into these implantable biocapsules can significantly increase the therapeutic effect of targeted drug delivery to treat neurodegenerative disorders, diabetes, and liver dysfunction [92-94]. Other forms of immunoprotective encapsulations such as alginate encapsulation [95], using hydrogels, and conformal coating of cells [96] as well as using polyelectrolyte are also utilized [97]. Another type of biological capsules is formed from phospholipids and liposome [98]. This type 
of particles was used in targeted drug delivery even before the invention of microfabrication techniques. To selectively attach to the cancerous tissues and enhance the site-specific feature of the liposome, ligands are also employed on its outer surface [99]. In addition, to extend the longevity of the liposome in blood circulation, it is chemically conjugated with synthetic polymers such as polyethylene glycol (PEG) [100]. To characterize and evaluate the liposome quality, a LOC platform containing embedded dielectric microsensors was also developed [101]. Daamen et al. [102] proposed a novel biocapsule termed as lyophilisome created from watersoluble macromolecules such as protein. This naturally prepared biocapsule not only facilitates targeted drug delivery but also its formation is amphiphilicity-independent. Utilizing this property, Etienne et al. [103] showed that albumin lyophilisome biocapsules can be a promising drug carrier to cure cancerous tissues. Amphiphilic polymeric vesicle, known as polymersome [104], is another artificial biocapsule used for targeted drug delivery. Most polymersomes contain two blocks of hydrophilic, such as PEG, and hydrophobic, such as polydimethylsiloxane (PDMS) and ploylactide (PLA) copolymers. Other amphiphilic nonlinear polymersomes with more complex morphologies, such as dendrimers and hyperbranched polymers [105], also exist. The performance of these synthetic drug carriers can be controlled using external stimuli such as temperature, light, hydrolysis, and $\mathrm{pH}$. Different approaches to form stimuli-responsive polymersomes were reviewed by Li and Keller [106].

3.2.1.2 Microparticles. To improve the efficacy of both oral and intravenous drug delivery methods, microparticles can be used as targeted drug carriers. The therapeutic agent is encapsulated in biodegradable polymers such as polyesters for in vivo drug delivery applications [107]. In this case, many factors such as the type of polymer, the size and shape of microparticles, and surface chemistry may have significant impact on the performance of drug delivery [107]. Biopolymers such as chitosan microparticles are also commonly used as efficient 
drug and protein carriers for several years [108, 109]. The particle size of typical chitosan microparticles, such as those prepared with tripolyphosphate (TPP) ranges from $500 \mu \mathrm{m}$ to $710 \mu \mathrm{m}$ [108]. Chitosan micro/nanoparticles can be used to selectively deliver the drug to the different body sites such as buccal gland, gastrointestinal tract, colon, etc [110].

3.2.1.3 Nanoparticles. Nanoparticles, with the size greater than $5 \mathrm{~nm}$ but smaller than $1000 \mathrm{~nm}$, are among the colloidal drug carriers which are extensively used in cancer therapy [111], gene delivery [112], and brain drug delivery [113]. Based on preparation techniques, nanoparticles can be categorized into nanocapsule, reservoir base, and nanosphere, and matrix base [114]. In nanocapsules a polymer membrane acting as a shell encapsulates the drug in a thin core [115]. Matrix system of nanospheres, with the thick polymeric network, enable the drug to distribute uniformly via particles [116]. Conventional nanoparticles in chemotherapy exploit the enhanced permeability and retention (EPR) effect of cancerous tissue to selectively bind to the timorous site, passive drug delivery. More smart nanoparticles are conjugated with ligands to selectively interact with the tumor receptors and release the anticancer drug at the targeted tissue, active drug delivery [91]. Using aptamers as a promising ligand, Xiao et al. [117] reported a novel targeted nanoparticle whose performance was efficient when tested in vitro. The state of art progresses in cancer therapy using nanoparticles is recently reviewed by Brigger et al. [116]. In addition to cancer therapy, nanoparticles can be diffused through the blood-brain barrier (BBB) to deliver the drug to the brain tumors $[118,119]$. Before the incorporating the drug into nanoparticles, the BBB used to be removed via invasive or non-invasive techniques prior to the drug administration. More details regarding the role of nanoparticles in both in vitro and in vivo experiments related to the brain drug delivery were reported by Kreuter [120].

\subsubsection{Production of smart particles using microfluidic technology}


Both conventional and soft microfabrication technologies can be implemented in drug delivery applications [121]. For the production of particles for drug delivery, both biocompatibility and non-immunogenicity of the implemented materials are extremely important. Conventional microfabrication techniques such as photolithography, wet/dry etching, vapour deposition rely mainly on silicon/glass substrates and clean room facilities [122]. However, soft microfabrication methods are based on biocompatible polymers such as PDMS/polymethylmethacrylate (PMMA) and require inexpensive facilities. These techniques such as soft lithography can also be combined with silicon technology, used as master mold, for rapid and inexpensive prototyping. Lu and Chen [123] reviewed these soft fabrication techniques for different biocompatible polymers. The recent review paper by Zhang et al. [124] evaluates the advances in materials used for drug delivery and synthesis. Fig. 13 summarizes some of the main microfabrication techniques.

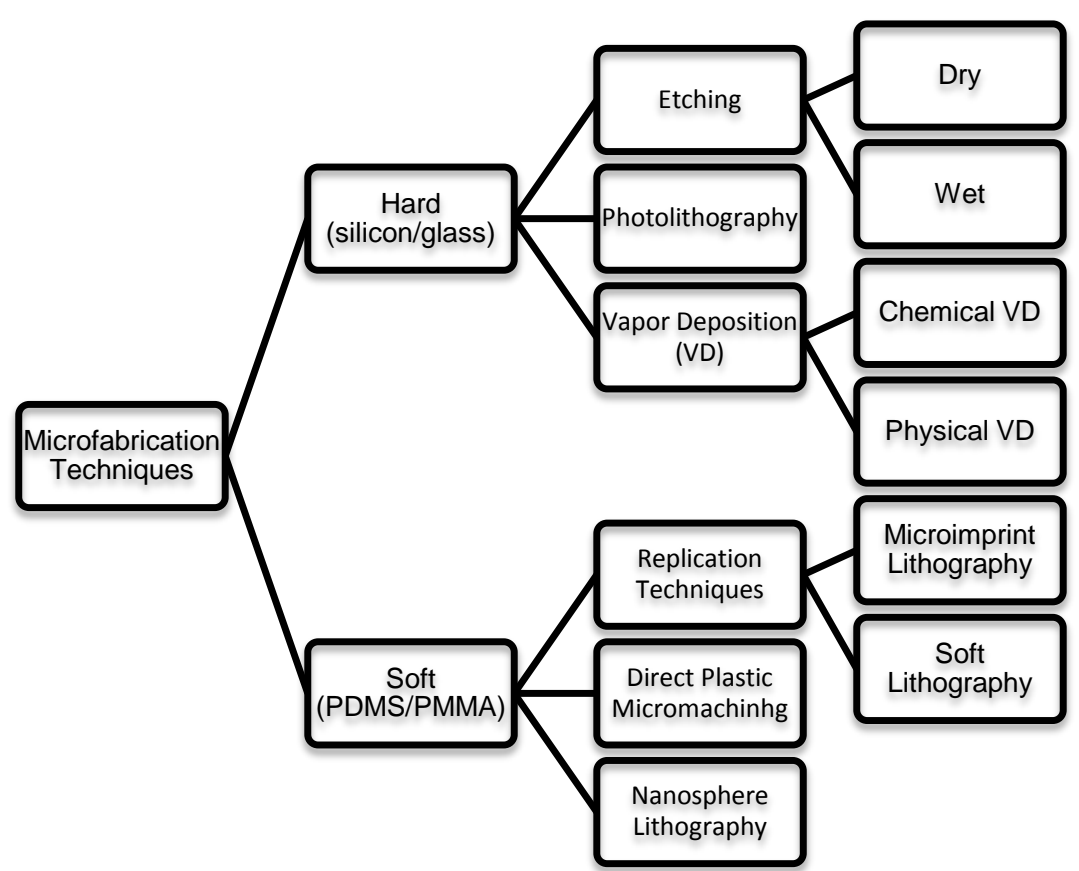

Fig. 12. Summary of the microfabrication techniques

3.2.2.1 Fabrication techniques of biocapsules. Among the different biocapsules introduced above, we focus here on the techniques used to fabricate selectively-permeable immunoisolation 
membrane. Some fabrication techniques for biocapsules used in cell-based drug delivery were reviewed earlier by Leoni and Desai [92]. Depending on the application, the pore size should be precisely controlled to allow the diffusion of therapeutic molecules and oxygen nutrients through the membrane while blocking the invasion of antibodies and complement proteins into the isolated cell/tissue. Beside the pore size, the length and shape of nanopores, which can also be considered as nanochannels, need to be fabricated accurately to filter and to affect the passage of damaging immunocytes [125]. Both top-down and bottom-up approaches can be employed to fabricate the semi-permeable membranes as summarized in Tables 2 and 3 . More details regarding these fabrication techniques are reported by Jeon et al. [126].

Table 2. Summary of top-down fabrication techniques for semi-permeable biocapsules

\begin{tabular}{|c|c|c|c|c|}
\hline Technique & Detailed Steps & Material & Pore size & Reference \\
\hline $\begin{array}{l}\text { Nanochannels surface } \\
\text { micromaching and } \\
\text { bulk silicon etching }\end{array}$ & $\begin{array}{l}\text { 1) Etching the nanochannels } \\
\text { 2) Growing a sacrificial oxide layer } \\
\text { (channel width) } \\
\text { 3) Depositing polysilicon (channel } \\
\text { structure) } \\
\text { 4) Planarization } \\
\text { 5) Boron-doping step (membrane } \\
\text { thickness) } \\
\text { 6) Depositing a protective nitride mask } \\
\text { 7) Back etching } \\
\text { 8) Etch mask removal } \\
\text { 9) Oxide layer removal }\end{array}$ & Silicon (Si) & $7-50 \mathrm{~nm}$ & [127] \\
\hline $\begin{array}{l}\text { Electron beam } \\
\text { lithography (EBL) } \\
\text { and reactive ion } \\
\text { etching (RIE) }\end{array}$ & $\begin{array}{l}\text { 1) Depositing SiN on Si wafer by low- } \\
\text { pressure chemical vapor deposition } \\
\text { (LPCVD) } \\
\text { 2) Photolithography followed by wet } \\
\text { etching } \\
\text { 3) Using EBL to produce pores on the } \\
\text { membrane } \\
\text { 4) Coupled } \mathrm{CHF}_{3} / \mathrm{O}_{2} \text { plasma treatment } \\
\text { to etch the desired pores }\end{array}$ & & $15-20 \mathrm{~nm}$ & [128] \\
\hline $\begin{array}{l}\text { EBL followed by } \\
\text { focused ion beam } \\
\text { (FIB) }\end{array}$ & $\begin{array}{l}\text { 1) Deposition SiN on silicon wafer } \\
\text { using LPCVD } \\
\text { 2) Photolithography followed by wet } \\
\text { etching } \\
\text { 3) Creating an initial pore at the centre } \\
\text { of the membrane using FIB } \\
\text { 4) Sculpting with a feedback } \\
\text { controlled ion-beam }\end{array}$ & Silicon nitride (SiN) & $1.8-60 \mathrm{~nm}$ & [129] \\
\hline $\begin{array}{l}\text { SiN micromachining } \\
\text { followed by FIB }\end{array}$ & $\begin{array}{l}\text { 1) Fabricating micropores supported } \\
\text { by a Si wafer } \\
\text { 2) Depositing SiN on the micropores }\end{array}$ & & $10-25 \mathrm{~nm}$ & [130] \\
\hline
\end{tabular}


using LPCVD

3) Using dry RIE followed by wet

etching to form a thin layer SiN on top

of the micropores

4) Using a dual FIB system to form the

nanopores

Table 3. Summary of bottom-up fabrication techniques for semi-permeable biocapsules

\begin{tabular}{|c|c|c|c|c|}
\hline Technique & $\begin{array}{l}\text { Detailed Steps } \\
\end{array}$ & Material & Pore size & Reference \\
\hline $\begin{array}{l}\text { Self-organized } \\
\text { electrochemical } \\
\text { formation }\end{array}$ & $\begin{array}{l}\text { 1) Applying current to oxidize the } \\
\text { metal (anode) } \\
\text { 2) Forming surface fluctuations by } \\
\text { a local field distribution } \\
\text { 3) Growing the initial pores by } \\
\text { filed/temperature- enhanced } \\
\text { decomposition } \\
\text { 4) Forming regular pores along the } \\
\text { thickness by removing the oxide } \\
\text { layer and repeating the anodization } \\
\text { process }\end{array}$ & $\begin{array}{l}\text { Aluminum/Titanium } \\
\text { (Inorganic) }\end{array}$ & $50-150 \mathrm{~nm}$ & {$[131,132]$} \\
\hline $\begin{array}{l}\text { Block copolymer } \\
\text { self-assembly }\end{array}$ & $\begin{array}{l}\text { 1) Forming nanoposts by mixing } \\
\text { polystyrene-block-PMMA and } \\
\text { PMMA homopolymer on silicon } \\
\text { dioxide layer } \\
\text { 2) Forming nanopores by } \\
\text { selectively removing the nanoposts } \\
\text { from the mixture using acetic acid }\end{array}$ & Organic copolymers & $10-40 \mathrm{~nm}$ & {$[133,134]$} \\
\hline
\end{tabular}

3.2.2.2 Fabrication Techniques of Microparticles. Similar to biocapsules, drug can be encapsulated in a wide range of biodegradable polymers such as polyglycolide (PGA), polylactic-co-glycolic acid (PLGA) and polylactide (PLA) to form polymeric microparticles. These microparticles are in the form of microspheres, microbeads and microcapsules. The preparation techniques of microspheres including phase separation, solvent emulsification/solvent evaporation, oil-in-water solvent evaporation, and oil-in-oil solvent removal techniques were previously reported [135]. Xu et al. [136] used microfluidic flow focusing devices to generate monodisperse microparticles. The drug loaded particles were fabricated from PLGA in the size range of 10 to 50 microns by altering the flow conditions. Because of several drawbacks of monolayer polymeric microparticles such as possibility of 
premature drug release, polymeric multilayer microparticles has been developed [137]. Lee et al. [138] used one-step solvent evaporation technique to fabricate the PLGA multilayer microparticles for drug delivery applications. Hsu et al. [139] used electrospraying to fabricate pectinate/alginate microspheres (PAMs). Employing poly-electrolyte multilayer coating, the core of the microsphere was further coated to control the release of the therapeutic agent (cisplatin) at the lower $\mathrm{pH}$ environment. It was shown that the coated PAMs can be used to effectively deliver the therapeutic dose of the drug to the colon tissue [139]. Other polymeric multilayer microparticles fabrication techniques are hot melt technology, dip/pan coating and precision microparticle fabrication technique [138] as well as layer-by-layer assembly [140].

To control the shape and structure of the scaffold-free micro/nanoparticles, Rolland et al. [83] modified the traditional imprint lithography by hydrophobizing the substrate. They called this fabrication technique particle replication in non-wetted template (PRINT). PRINT can facilitate the encapsulation of a wide variety of therapeutic agents. The applications of PRINT in producing aerosol particles used in respiratory drug delivery systems were also investigated [141]. Other microfabrication techniques used in particulate drug delivery applications such as step and flash imprint lithography (S-FIL), film stretching and flow lithography were reviewed in the literature $[142,143]$. In addition, soft lithographic technologies such as microfluid contact printing ( $\mu \mathrm{FCP})$ [144], microtransfer molding ( $\mu \mathrm{TM})$ [145] and continuous flow lithography [146] can also be used to fabricate the drug carrier polymeric microparticles. Guan et al. [147] introduced microcontact hot printing ( $\mu \mathrm{CHP}$ ) technique to fabricate polymeric microparticles from micropillar/well PDMS stamps.

Microparticles can also be used to increase the bioavailability of the drugs in oral delivery applications, in particular for delivery of large macromolecules like peptide and protein 
which otherwise would be decomposed into smaller molecules through the acidic environment of the stomach [93]. In this case, flat microparticles are preferred over the spherical particles due to the higher contact area with the intestinal lining [93]. Different microfabrication technologies of microparticles for oral drug delivery systems are recently reviewed by Sant et al. [148]. Furthermore, microfabrication techniques can also be used to fabricate smart intravenously injected microparticles [93]. The drug is inserted into the microparticle reservoir, and the surface of the microparticles is chemically modified with ligands to actively target the unhealthy tissues. In this sense, the fabrication techniques are similar to that of the nanoparticles used in cancer therapy and will be further discussed in the following section.

3.2.2.3 Fabrication techniques of nanoparticles. To be injected intravenously as well as internalized with the tissue cells, particle size should be smaller than $200 \mathrm{~nm}$ [149]. Unique properties of nanoparticles make them an excellent choice for drug delivery in vital tissues such as brain and lungs. Yet, several design factors should be considered in the fabrication of nanoparticles since nonspecific binding of these particles to healthy tissues could have catastrophic results. Depending on the application, the morphology, size, charge and coating materials of particles should be devised accordingly. Drug loading method, binding of targeted ligands and drug releasing technique are among the other designing criteria influencing the nanoparticles fabrication method. The shape of nanoparticles can also greatly influence their therapeutic efficacy [150].

Both top-down, such as nanoimprint lithography, and bottom-up, such as molecular selfassembly, or the combination of both approaches, can be used to fabricate nanoparticles. Topdown production techniques to fabricate nanoparticles with special emphasize given on PRINT method is presented by Canelas et al. [143]. Chan and Kwok [151] reviewed two main bottom- 
up processes of nanaoparticles fabrication including solvent precipitation (such as hydrosol production and flash nanoprecipitation) and controlled droplets evaporation (such as spray drying and electrospraying).

Magnetic nanoparticles are another type of smart particles with stimuli-responsive capability which can be used in targeted drug delivery. The detailed fabrication processes of magnetic nanoparticles, such as fabrication of the core and coating techniques with organic or inorganic materials, are reviewed by Veiseh et al. [152].

Among polymeric biodegradable polymers, PLGA-based nanoparticles have attracted a lot of attention in drug delivery applications. A thorough review of the detailed applications of such polymeric nanoparticles in targeted drug delivery systems is presented by Danhier et al. [153]. To deliver the chemotherapeutic drug to cancerous tissues, in addition to polymeric carriers and nanoshells, other nanocarriers including fusion protein, carbon nanotube, micelles, polymer-conjugate drug, dendrimers, and liposomes can be used [91]. Furthermore, gold nanoparticles have exclusive physicochemical properties such as high biocompatibility and localized surface plasmon resonance which can be used as effective anticancer drug carrier. Production of these gold nanoparticles and their design parameters in delivering the drug to pancreatic cancer are reviewed by Patra et al. [154]. Nanoparticles fabricated from rapidly biodegradable polymers such as polybutylcyanoacrylate (PBCA) can also be used to overcome the blood brain barrier and carry the drug to the desired brain region. Emulsion/dispersion/interfacial polymerizations are among the common production techniques of PBCA-based nanoparticles used to deliver the drug to the brain for Alzheimer's disease treatment. Detailed fabrication techniques are reviewed Roney et al. [155]. 


\subsection{Drug delivery on the organism level}

\subsubsection{Micro needles}

At organism level, the most common drug delivering method is injection with a needle. This section focuses on the design and fabrication of microneedles for drug delivery. In general, microneedles can be categorised in four different types: (i) solid microneedles for skin pretreatment to increase skin permeability, (ii) microneedles coated with drug that dissolves off in the skin, (iii) polymeric microneedles that encapsulate drug and fully dissolve in the skin and (iv) hollow microneedles for drug infusion into the skin, Fig. 13.

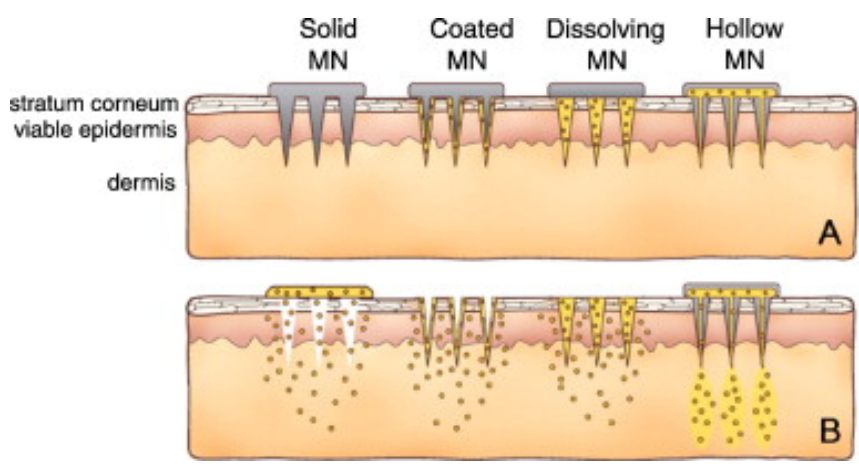

Fig. 13. Methods of drug delivery using microneedles. Reprinted with permission from [156].

Microneedles have been fabricated from a wide range of materials such as metal, polymer, glass and ceramic with different shapes as needed for diverse applications. The fabrication process is based on the conventional microfabrication techniques of deposition, etching, and replicating microstructures utilizing photolithography, silicon etching, laser cutting, metal electroplating, metal electropolishing and micromolding.

3.3.1.1 Solid microneedles. A sharp solid microneedle is used to insert into the skin to make smaller pores. After the insertion, the needle can be removed. A drug formulation then can be applied on the punctured skin, either with a drug-loaded patch or a semi-solid topical formulation such as cream, gel or lotion. Various materials can be used for the fabrication of 
solid microneedles. The three basic requirements are mechanical strength through choice of materials, geometry of the tip and reducing force when applying to the skin. Materials suitable for making microneedles are silicon [157-163], metal [164, 165], polymer [166-172] and ceramic [173-175]. Furthermore, some microneedles can be fabricated on a cylindrical surface that then is applied to skin as a roller [176-179].

3.3.1.2 Hollow microneedles. With hollow microneedles, the drug is infused or diffuses into the skin through the channel inside the microneedle. Microelectromechanical systems (MEMS) techniques have been used to directly fabricate hollow microneedles. David et al. employed laser micromachining for the fabrication of hollow metal microneedles [165]. Deep reactive ion etching was employed to fabricate silicon microneedles [180, 181]. Luttge et al. used a lithographic moulding technique to make out-of-plane polymeric hollow microneedles [182]. Perennes et al. fabricated sharp bevelled tip hollow microneedle arrays deep X-ray photolithography [183]. Wet chemical etching was reported for making a microneedle array with an integrated PZT insulin pump [184].

Yu et al. fabricated cylindrical hollow microneedles using a $\mathrm{SiO}_{2}$ mask, wet etching and deep reactive ion etching [185]. Hollow microneedles with sharp tips were made by combining Bosch deep reactive ion etching with wet etching [184]. Hollow microneedles with a tapered shape utilized wet and dry etching technologies [186] or combining DRIE, diamond blade circular sawing and isotropic etching [187]. In addition, conventional methods were utilized to fabricate hollow microneedles made of glass or polymer. For instance, hollow glass microneedles were made using traditional drawn glass micropipette techniques [188]. Hollow polymer microneedles can be created either by drilling to make a bore hole and milling to make sharp tip [189]. 
Häfeli et al. developed a miniature syringe connected to a PDMS reservoir filled with a drug to deliver liquid formulations into a hollow microneedles [190], Fig. 15. Various actuation schemes have been used to control the flow of drug through hollow microneedles: pressure from $\mathrm{CO}_{2}$ gas tank [191], a spring [192], piezoelectric (PZT) linear servo motor [193], micro-gear pump [194], and piezoelectric micropump [195].

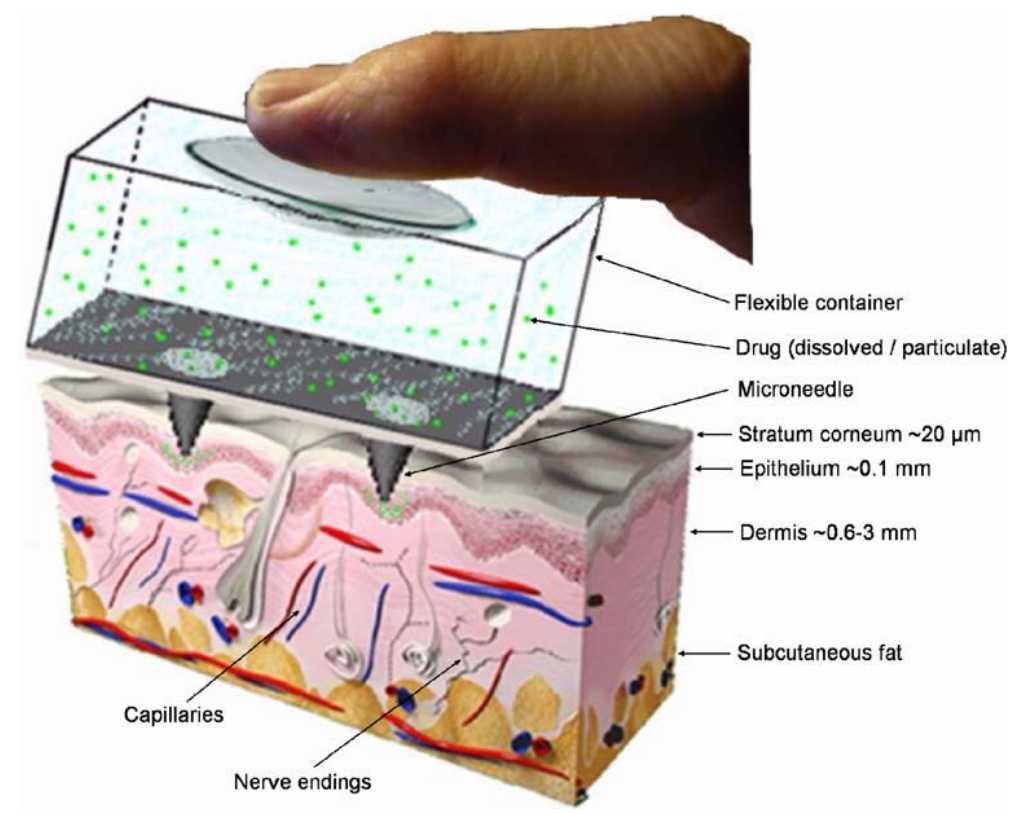

Fig. 14. Concept of a miniature syringe attached to a PDMS reservoir (not to scale). Once pressing a finger on the deformable drug reservoir, the needles are driven into the skin and the drug suspension or solution is injected into the epidermal skin. Reprinted with permission from [190].

There are two basic configurations of hollow microneedles: single needle and an array of needles. Wonglertnirant et al. investigated several performance factors such as administration volume, formulation, and depth penetration of single microneedles [196]. In contrast to a single needle, an array of multiple hollow microneedles can deliver liquid formulations to a wider area allowing rapid intradermal delivery [192]. 
3.3.1.3 Coated microneedles. A microneedle coated with a drug using a water-soluble formulation is first inserted into the skin. After the insertion, the drug is dissolved off into the skin and the microneedle can be then removed.

Dipping and spraying using an aqueous solution are the most common ways to coat microneedles. A high viscosity of the solution would allow more drug to retain on the microneedles [197, 198]. The different coating techniques are dipping microneedles once or many times into a coating solution bath [199], dipping each microneedle into microwells filled with coating solution [197], dipping into a thin film of coating solution formed on the surface of a roller [200], layer-by-layer coating [201], or spraying using an atomizer [202].

The considerations for coating a drug formulation onto a microneedle are [197, 198]: (i) the thickness of coating layer is uniform by controlling wetting and spreading of drug solution, (ii) coating formulation is water-soluble, (iii) the mechanical strength of a dried coating layer is high enough to insert into the skin, (iv) solvent and coating solution are safe for human health, and (v) the coating process does not affect the drug. During the coating process, a number of different surfactant and thickening agents such as Tween 20 [203] and Poloxamer 188 can be used [204]. There many compounds that can be coated on microneedles are for example fluorescein [205], calcein [197], vitamin B [197]), macromolecules [198], vaccines [206], DNA [207], micron-scale particles [197].

3.3.1.4 Dissolvable microneedles. Dissolvable microneedles were made of water-soluble or biodegradable polymers. After insertion into the skins, microneedles ecapsulating the drug are dissolved completely and leave no sharps waste. 
Generally, a micromould, a polymer melt and in-situ polymerization of liquid monomer were used to fabricate dissolvable microneedles [156]. Some heat-sensitive compounds, such as proteins and antigens can be encapsulated in dissolvable microneedles and should be solidified at the specific conditions to maintain their activities [156]. For instance, a microneedle encapsulating human growth hormone was fabricated in a vacuum dryer [208]. The time of insertion into the skins depends on the designs and material. A quick separation of the arrowhead tips from the shafts within seconds can be carried out leaving a dissolution of drug in skin [209], whereas biodegradable polymer microneedles encapsulated drug can stay in skin for hours to months with the purpose of controlled-release delivery [210]. Microneedles encapsulating hydrogel microparticles were released successfully into the skin within one hour by hydrogel swelling [211]. Sometimes, drugs only can only be encapsulated on the microneedle tips using two-layered dissolvable microneedles [208] or multi-layer microneedles using polymer particlebased micromolding method [212]. Furthermore, localization of drug in the microneedle tip was fabricated by either casting a highly concentrated polymer solution or adding an air bubble at the base of the microneedle [213].

\subsubsection{Organs on a chip}

Recently, much attention has been paid on the reconstruction of tissues and organs by combining cells and nanotechnology [214]. LOC technologies have been utilized to create devices which can mimic biological system, such as lung [3], artery [215] and liver [216].

Micromachined compartments have ability to create organ functions [217]. Compartmentalization is described as the creation of separations between differential environments, as shown in Fig. 15. This approach can mimics organ structure and functions. Tissues were specialized in well-defined environments and they can interact with each other via microfluidic channels to generate organ functions. These systems represent the in vivo organ 
micro environments, providing an alternative, low-cost, preclinical test platform, especially for drug developments. Several in vitro organ systems have been fabricated using compartmentalized microengineering methods such as kidney [67], intestine [69, 218], cartilage [219]. Multicompartment microfluidic-based devices can therefore be used to enhance the drug development process [220].

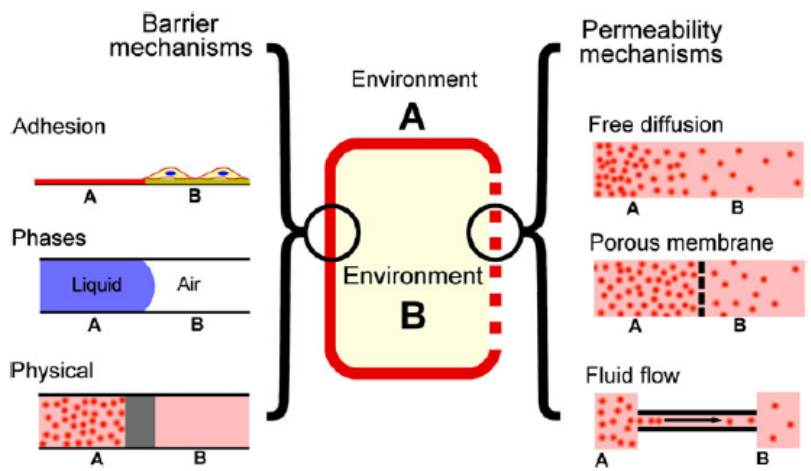

Fig. 15. Schematic representation of compartmentalization between environments A and B. Reprinted with permission from [217].

Drug delivery systems for organs and living organisms on a chip create the pharmacokinetic models used to assess toxicity and metabolism of drugs and chemicals [217]. For instance, toxicity of livers can be modelled and evaluated using these devices [221, 222]. Fig. 16 shows a typical organ-on-a-chip model. Cells representing certain organs communicating via microfluidic channels are cultured in the different compartments.
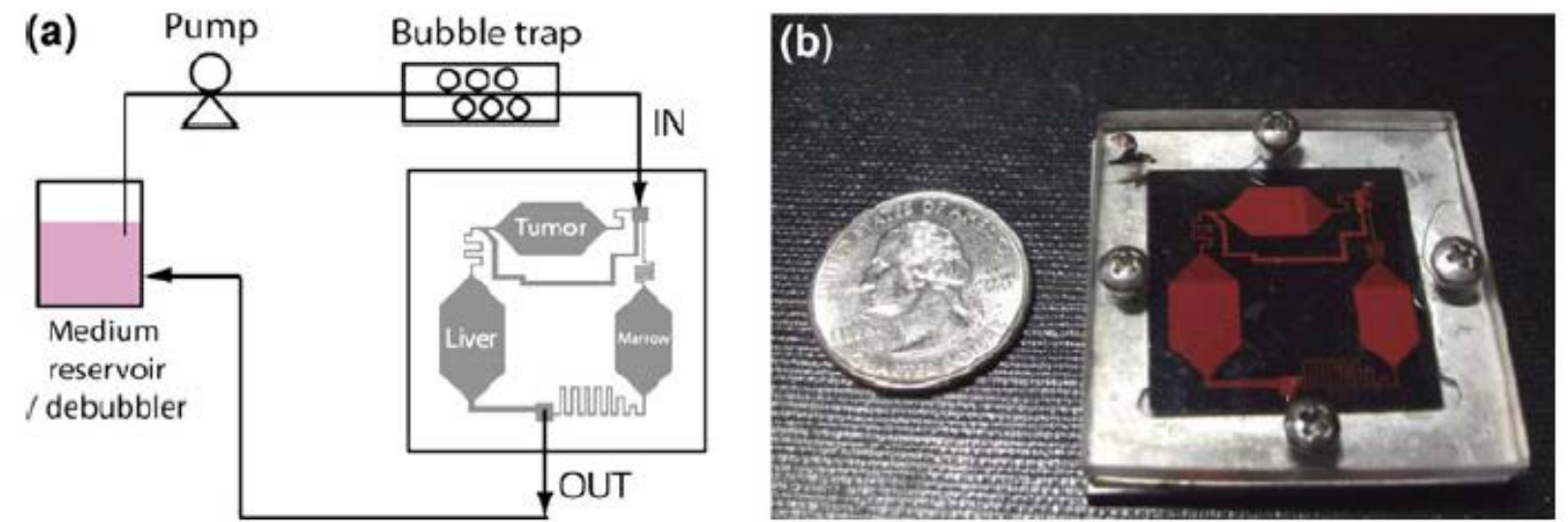

Fig. 16. Organs on a chip. (a) Schematic representation and (b) experimental setup for a system in which the liver, bone marrow, and a tumor are allowed to interact. Reprinted with permission from [222]. 


\subsubsection{Implanted microfluidic drug delivery devices}

In order to distinguish microfluidic drug delivery devices from other micro devices for drug delivery, this section only focuses on recently developed devices using microfluidic components such as micropumps and microvalves for fluid manipulation. These devices deliver drug to a specific target using convective transport, rather than pure diffusion-based drug delivery.

Diffusion-based drug delivery of a drug from a self-contained reservoir provides continuous release over an extended period of time. Drug release can take several hours to days depending on the diffusion coefficient of the drug [223]. In such systems, dose initiation time by diffusion can be manipulated, but generally delivery rate remains fixed to a relatively slow rate [224]. For some applications, it is desirable to have a rapid dosage delivery, a non-continuous delivery pattern, or a pulsatile delivery pattern to better mimic a physiological release profile such as that of insulin [224]. For uses in special areas such as brain, drugs delivered by diffusion from polymer implants or bolus injections generally able to penetrate $3 \mathrm{~mm}$ from the implant [225]. Consequently, some drugs are desirable to penetrate further into the tissue by convective transport with an applied pressure gradient rather than with pure diffusion along a concentration gradient [226-228].

Active delivery of drug from a reservoir in an implantable microfluidic device to a specific target is generally carried out with a power source. Actuation can be either manual [229], by applying a voltage [230, 231] or wirelessly with a magnetic field [232].

Lo et al. [229] fabricated an implantable drug delivery device comprising of a refillable drug reservoir, flexible cannula, check valve and suture tabs using three layers of PDMS to deliver drugs for treating chronic ocular diseases. Mechanically actuated by a patient's finger, a specific 
dose of drug can be dispensed from the device, Figure 17. The device has a thickness of less than $2 \mathrm{~mm}$. Flow rates of $1.57 \pm 0.2 \mu \mathrm{L} / \mathrm{sec}$ and $0.61 \pm 0.2 \mu \mathrm{L} / \mathrm{sec}$ under $500 \mathrm{mmHg}$ and $250 \mathrm{mmHg}$ of applied pressure, respectively, were obtained in benchtop experiments. In order to replace the manual actuation, electrolysis of water into gaseous oxygen and hydrogen was exploited to make an micropump [230, 231]. The pump generates sufficient pressure in the drug reservoir to deliver an accurate amount of $250 \mathrm{~nL}$ into the intraocular space through a parylene cannula and a oneway check valve. Pirmoradi et al. [232] have reported the design and the fabrication of a magnetically actuated ocular implant for delivery of suitable dosage of docetaxel for treatment of diabetic retinopathy. It consist of a drug-loaded reservoir (Ø6 mm×550 $\mu \mathrm{m}$ ), sealed by an elastic magnetic PDMS membrane $(\varnothing 6 \mathrm{~mm} \times 40 \mu \mathrm{m})$ with a laser-drilled aperture $(\sim 100 \times 100$ $\mu^{2}$ ). The magnetic PDMS membrane is deformed by applying a magnetic field of $255 \mathrm{mT}$. Membrane deformation results in a discharge of the drug solution from the device at a release rate of $171 \pm 16.7 \mathrm{ng}$ per actuation.
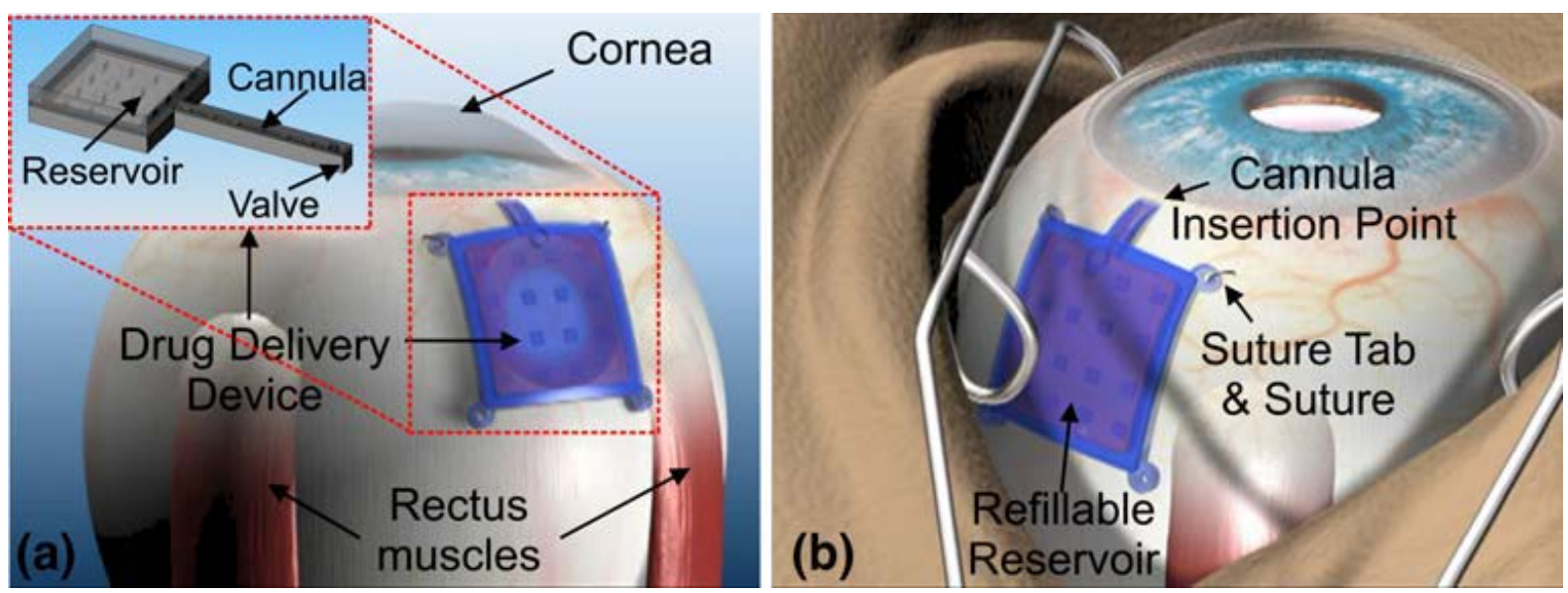

Fig. 17. (a) Schematic of a drug delivery device over an eye. The device must fit between the rectus muscles. The whole device including reservoir, cannula and valve possess a small thickness to avoid irritation $(<2 \mathrm{~mm})$; (b) Illustration of an implanted drug delivery device. The refillable reservoir is placed underneath the conjunctiva (a thin layer of tissue covering the sclera) and sutured to the sclera (white portion of the eye). The cannula is inserted through the sclera into the eye. Reprinted with permission from [229].

Elman et al. [233] developed an implanted device for rapid drug delivery for ambulatory emergency care. The device consists of a large single reservoir layer; a membrane layer that 
seals the drug reservoir hermetically, and an actuation layer. Actuation layer is defined by titanium microresistors to generate bubbles through heating once activated. In order to prevent drug degradation because of heating, film boiling regime is desired to insulate the bulk of the drug solution from the surface of the heater. Pressure rise in the reservoir by generated bubbles ruptures the sealing membrane made of silicon nitride. The drug is ejected out at a delivery rate of $20 \mu \mathrm{L}$ over 45 seconds. Vasopressin was used as a model drug for cardiac resuscitation.

Localized electrokinetic forces were used as another approach for drug ejection in a microwellbased implantable drug delivery device [224]. The device consists of a silicon-based structure and a PDMS backing. The silicon layer contained the drug wells and the upper electrodes, while the lower electrodes were deposited on the PDMS layer. Each well had a volume of approximately $100 \mathrm{~nL}$. The release time and the release rate of chemicals stored in the wells were controlled by changing the applied potentials to the electrodes.

Foley et al. [226] fabricated and characterized an implantable microfluidic device for chronic convection enhanced delivery (CED) protocols. The device was made of a flexible channel in parylene-C that is supported by a biodegradable poly(DL-lactide-co-glycolide), PLGA, scaffold during its insertion into a tissue. After the scaffold is dissolved, only the flexible channels are left in the tissue enabling a reproducible injection of fluid into neural tissue. Results obtained of a test infusion of a food dye into a $0.6 \% \mathrm{wt} / \mathrm{v}$ agarose gel brain phantom at a flow rate of $0.1 \mu \mathrm{l} / \mathrm{min}$. The observed dye distribution revealed an approximated spherical distribution of an ideal point source. The average flow rate obtained for in vivo experiments on a mice was $0.09 \pm 0.005 \mu \mathrm{l} / \mathrm{min}(\mathrm{n}=5)$, at a driving pressure of $3.45 \mathrm{kPa}$. 
In addition to the above mentioned works on implanted microfluidic drug delivery devices, many devices were reported in the literature focusing on the integration of microelectrodes as neural probes with microfluidic drug delivery channels for brainmachine interfaces (BMI) [234237]. Such micro devices are generally used for simultaneous drug delivery and in vivo electrophysiology recordings which are out the scope of this paper. Furthermore, there are many interesting investigations on microfluidics-based intracochlear drug delivery devices [238-240] which are beyond the scope of this paper.

\section{Conclusions}

The present paper reviews the use of micro- nanotechnology and LOC technology in the design and development of drug delivery systems. Existing micromachining capabilities allow the integration of fluid handling components on a single device leading to the concept of LOC. The technology has a broad impact on drug delivery from the early drug discovery and screening stage to the final targeted and controlled delivery stage. As illustrated throughout the review, LOC technology allows controlled delivery and evaluation at cellular, to tissue to organism level. At cellular level, LOC technology provides a platform for controlled drug delivery to cells grown in-vitro on the same device. The possibility of well controlled distribution of drug concentration and growing cells on a chip makes high-throughput combinatorial drug screening possible. The same concept can be extended to tissue and organ level, where in-vivo physiological conditions can be recreated on a chip leading to fast and low-cost drug screening. Micro- and nanotechnologies are ideal for the synthesis of smart particles working as drug carriers. At the organism level, LOC can work as a platform for testing the effect of drugs on small organisms. Furthermore, LOC technology enhances traditional delivery methods such as injection by introducing microneedles integrated with a complex liquid handling system for targeted and rate-controlled delivery. The unique advantages of compactness and controllability 
allows the development of implantable drug delivery devices to become reality. The present review shows that LOC technology can bridge the gap between pharmaceutical industry and drug delivery industry to provide better therapeutic solutions to the end users.

\section{References}

[1] R. Lu, Øie, Svein, Cellular Drug Delivery: Principles and Practice, Humana Press Inc., Totowa, 2004.

[2] M.-H. Wu, S.-B. Huang, G.-B. Lee, Microfluidic cell culture systems for drug research, Lab on a Chip, 10 (2010) 939-956.

[3] D. Huh, B.D. Matthews, A. Mammoto, M. Montoya-Zavala, H.Y. Hsin, D.E. Ingber, Reconstituting Organ-Level Lung Functions on a Chip, Science, 328 (2010) 1662-1668.

[4] A. Khademhosseini, R. Langer, J. Borenstein, J.P. Vacanti, Microscale technologies for tissue engineering and biology, Proceedings of the National Academy of Sciences of the United States of America, 103 (2006) 2480-2487.

[5] S. Mao, D. Gao, W. Liu, H. Wei, J.-M. Lin, Imitation of drug metabolism in human liver and cytotoxicity assay using a microfluidic device coupled to mass spectrometric detection, Lab on a Chip, 12 (2012) 219-226.

[6] B. Ma, G. Zhang, J. Qin, B. Lin, Characterization of drug metabolites and cytotoxicity assay simultaneously using an integrated microfluidic device, Lab on a Chip, 9 (2009) 232-238.

[7] L. Kang, B.G. Chung, R. Langer, A. Khademhosseini, Microfluidics for drug discovery and development: From target selection to product lifecycle management, Drug Discovery Today, 13 (2008) 1-13.

[8] J. Hong, J.B. Edel, A.J. deMello, Micro- and nanofluidic systems for high-throughput biological screening, Drug Discovery Today, 14 (2009) 134-146.

[9] P.S. Dittrich, A. Manz, Lab-on-a-chip: microfluidics in drug discovery, Nat Rev Drug Discov, 5 (2006) 210-218.

[10] I. Meyvantsson, D.J. Beebe, Cell Culture Models in Microfluidic Systems, Annual Review of Analytical Chemistry, 1 (2008) 423-449.

[11] A. Tirella, M. Marano, F. Vozzi, A. Ahluwalia, A microfluidic gradient maker for toxicity testing of bupivacaine and lidocaine, Toxicology in Vitro, 22 (2008) 1957-1964.

[12] J. Zguris, L. Itle, D. Hayes, M. Pishko, Microreactor Microfluidic Systems with Human Microsomes and Hepatocytes for use in Metabolite Studies, Biomedical Microdevices, 7 (2005) 117-125.

[13] Y.-C. Toh, T.C. Lim, D. Tai, G. Xiao, D. van Noort, H. Yu, A microfluidic 3D hepatocyte chip for drug toxicity testing, Lab on a Chip, 9 (2009) 2026-2035.

[14] G.M. Walker, N. Monteiro-Riviere, J. Rouse, A.T. O'Neill, A linear dilution microfluidic device for cytotoxicity assays, Lab on a Chip, 7 (2007) 226-232.

[15] D. Liu, L. Wang, R. Zhong, B. Li, N. Ye, X. Liu, B. Lin, Parallel microfluidic networks for studying cellular response to chemical modulation, Journal of Biotechnology, 131 (2007) 286292.

[16] T.M. Keenan, A. Folch, Biomolecular gradients in cell culture systems, Lab on a Chip, 8 (2008) 34-57.

[17] B.G. Chung, J. Choo, Microfluidic gradient platforms for controlling cellular behavior, ELECTROPHORESIS, 31 (2010) 3014-3027. 
[18] V.V. Abhyankar, M.A. Lokuta, A. Huttenlocher, D.J. Beebe, Characterization of a membrane-based gradient generator for use in cell-signaling studies, Lab on a Chip, 6 (2006) 389-393.

[19] B. Mosadegh, M. Agarwal, H. Tavana, T. Bersano-Begey, Y.-s. Torisawa, M. Morell, M.J. Wyatt, K.S. O'Shea, K.F. Barald, S. Takayama, Uniform cell seeding and generation of overlapping gradient profiles in a multiplexed microchamber device with normally-closed valves, Lab on a Chip, 10 (2010) 2959-2964.

[20] C.W. Frevert, G. Boggy, T.M. Keenan, A. Folch, Measurement of cell migration in response to an evolving radial chemokine gradient triggered by a microvalve, Lab on a Chip, 6 (2006) 849-856.

[21] N.L. Jeon, S.K.W. Dertinger, D.T. Chiu, I.S. Choi, A.D. Stroock, G.M. Whitesides, Generation of Solution and Surface Gradients Using Microfluidic Systems, Langmuir, 16 (2000) 8311-8316.

[22] N. Li Jeon, H. Baskaran, S.K.W. Dertinger, G.M. Whitesides, L. Van De Water, M. Toner, Neutrophil chemotaxis in linear and complex gradients of interleukin-8 formed in a microfabricated device, Nat Biotech, 20 (2002) 826-830.

[23] N. Ye, J. Qin, W. Shi, X. Liu, B. Lin, Cell-based high content screening using an integrated microfluidic device, Lab on a Chip, 7 (2007) 1696-1704.

[24] W. Siyan, Y. Feng, Z. Lichuan, W. Jiarui, W. Yingyan, J. Li, L. Bingcheng, W. Qi, Application of microfluidic gradient chip in the analysis of lung cancer chemotherapy resistance, Journal of Pharmaceutical and Biomedical Analysis, 49 (2009) 806-810.

[25] J. Ruan, L. Wang, M. Xu, D. Cui, X. Zhou, D. Liu, Fabrication of a microfluidic chip containing dam, weirs and gradient generator for studying cellular response to chemical modulation, Materials Science and Engineering: C, 29 (2009) 674-679.

[26] S. Sugiura, K. Hattori, T. Kanamori, Microfluidic Serial Dilution Cell-Based Assay for Analyzing Drug Dose Response over a Wide Concentration Range, Analytical Chemistry, 82 (2010) 8278-8282.

[27] D. Irimia, D.A. Geba, M. Toner, Universal Microfluidic Gradient Generator, Analytical Chemistry, 78 (2006) 3472-3477.

[28] C. Beta, T. Frohlich, H.U. Bodeker, E. Bodenschatz, Chemotaxis in microfluidic devices-a study of flow effects, Lab on a Chip, 8 (2008) 1087-1096.

[29] G.M. Walker, J. Sai, A. Richmond, M. Stremler, C.Y. Chung, J.P. Wikswo, Effects of flow and diffusion on chemotaxis studies in a microfabricated gradient generator, Lab on a Chip, 5 (2005) 611-618.

[30] J. Atencia, J. Morrow, L.E. Locascio, The microfluidic palette: A diffusive gradient generator with spatio-temporal control, Lab on a Chip, 9 (2009) 2707-2714.

[31] V. Vickerman, J. Blundo, S. Chung, R. Kamm, Design, fabrication and implementation of a novel multi-parameter control microfluidic platform for three-dimensional cell culture and realtime imaging, Lab on a Chip, 8 (2008) 1468-1477.

[32] Y. Shin, S. Han, J.S. Jeon, K. Yamamoto, I.K. Zervantonakis, R. Sudo, R.D. Kamm, S. Chung, Microfluidic assay for simultaneous culture of multiple cell types on surfaces or within hydrogels, Nat. Protocols, 7 (2012) 1247-1259.

[33] F. Hassan, S. Islam, M.M. Mu, H. Ito, N. Koide, I. Mori, T. Yoshida, T. Yokochi, Lipopolysaccharide Prevents Doxorubicin-Induced Apoptosis in RAW 264.7 Macrophage Cells by Inhibiting p53 Activation, Molecular Cancer Research, 3 (2005) 373-379.

[34] J.-H. Lee, D.G. Kim, T.J. Bae, K. Rho, J.-T. Kim, J.-J. Lee, Y. Jang, B.C. Kim, K.M. Park, S. Kim, CDA: Combinatorial Drug Discovery Using Transcriptional Response Modules, PLoS ONE, 7 (2012) e42573.

[35] R.J. Pomerantz, D.L. Horn, Twenty years of therapy for HIV-1 infection, Nature Medicine, 9 (2003) 867-873. 
[36] K. Lee, C. Kim, Y. Kim, B. Ahn, J. Bang, J. Kim, R. Panchapakesan, Y.-K. Yoon, J. Kang, K. Oh, Microfluidic concentration-on-demand combinatorial dilutions, Microfluidics and Nanofluidics, 11 (2011) 75-86.

[37] K. Lee, C. Kim, G. Jung, T. Kim, J. Kang, K. Oh, Microfluidic network-based combinatorial dilution device for high throughput screening and optimization, Microfluidics and Nanofluidics, 8 (2010) 677-685.

[38] W.F. Maier, K. Stöwe, S. Sieg, Combinatorial and High-Throughput Materials Science, Angewandte Chemie International Edition, 46 (2007) 6016-6067.

[39] M.C. Liu, D. Ho, Y.-C. Tai, Monolithic fabrication of three-dimensional microfluidic networks for constructing cell culture array with an integrated combinatorial mixer, Sensors and Actuators B: Chemical, 129 (2008) 826-833.

[40] B.R. Schudel, C.J. Choi, B.T. Cunningham, P.J.A. Kenis, Microfluidic chip for combinatorial mixing and screening of assays, Lab on a Chip, 9 (2009) 1676-1680.

[41] Y.-H. Jang, M.J. Hancock, S.B. Kim, S. Selimovic, W.Y. Sim, H. Bae, A. Khademhosseini, An integrated microfluidic device for two-dimensional combinatorial dilution, Lab on a Chip, 11 (2011) 3277-3286.

[42] D.A. LaVan, D.M. Lynn, R. Langer, Moving smaller in drug discovery and delivery, Nature Reviews Drug Discovery, 1 (2002) 77-83.

[43] R.S. Shawgo, A.C. Richards Grayson, Y. Li, M.J. Cima, BioMEMS for drug delivery, Current Opinion in Solid State and Materials Science, 6 (2002) 329-334.

[44] S. Zafar Razzacki, P.K. Thwar, M. Yang, V.M. Ugaz, M.A. Burns, Integrated microsystems for controlled drug delivery, Advanced Drug Delivery Reviews, 56 (2004) 185-198.

[45] B.H. Weigl, R.L. Bardell, C.R. Cabrera, Lab-on-a-chip for drug development, Advanced Drug Delivery Reviews, 55 (2003) 349-377.

[46] C.D. Chin, V. Linder, S.K. Sia, Lab-on-a-chip devices for global health: Past studies and future opportunities, Lab on a Chip, 7 (2007) 41-57.

[47] P. Neuži, S. Giselbrecht, K. Länge, T.J. Huang, A. Manz, Revisiting lab-on-a-chip technology for drug discovery, Nat Rev Drug Discov, 11 (2012) 620-632.

[48] D.A. LaVan, T. McGuire, R. Langer, Small-scale systems for in vivo drug delivery, Nature Biotechnology, 21 (2003) 1184-1191.

[49] M. Biondi, F. Ungaro, F. Quaglia, P.A. Netti, Controlled drug delivery in tissue engineering, Advanced Drug Delivery Reviews, 60 (2008) 229-242.

[50] F. Rehfeldt, A.J. Engler, A. Eckhardt, F. Ahmed, D.E. Discher, Cell responses to the mechanochemical microenvironment-Implications for regenerative medicine and drug delivery, Advanced Drug Delivery Reviews, 59 (2007) 1329-1339.

[51] A.M. Ghaemmaghami, M.J. Hancock, H. Harrington, H. Kaji, A. Khademhosseini, Biomimetic tissues on a chip for drug discovery, Drug Discovery Today, 17 (2012) 173-181.

[52] D. Huh, Y.-s. Torisawa, G.A. Hamilton, H.J. Kim, D.E. Ingber, Microengineered physiological biomimicry: Organs-on-Chips, Lab on a Chip, 12 (2012) 2156-2164.

[53] M.N.V.R. Kumar, Handbook of Particulate Drug Delivery, American Scientific Publishers: Los Angeles, CA, USA, 2008.

[54] Y.-C. Kim, J.-H. Park, M.R. Prausnitz, Microneedles for drug and vaccine delivery, Advanced Drug Delivery Reviews, 64 (2012) 1547-1568.

[55] R. Farra, N.F. Sheppard, L. McCabe, R.M. Neer, J.M. Anderson, J.T. Santini, M.J. Cima, R. Langer, First-in-Human Testing of a Wirelessly Controlled Drug Delivery Microchip, Science Translational Medicine, 4 (2012) 122ra121.

[56] J.T. Santini, M.J. Cima, R. Langer, A controlled-release microchip, Nature, 397 (1999) 335338.

[57] J.T. Santini Jr, A.C. Richards, R. Scheidt, M.J. Cima, R. Langer, Microchips as controlled drug-delivery devices, Angewandte Chemie International Edition, 39 (2000) 2396-2407. 
[58] J.W. Park, B. Vahidi, A.M. Taylor, S.W. Rhee, N.L. Jeon, Microfluidic culture platform for neuroscience research, Nature Protocols, 1 (2006) 2128-2136.

[59] S. Harris, M. Shuler, Growth of endothelial cells on microfabricated silicon nitride membranes for an in vitro model of the blood-brain barrier, Biotechnology and Bioprocess Engineering, 8 (2003) 246-251.

[60] N.T. Elliott, F. Yuan, A review of three-dimensional in vitro tissue models for drug discovery and transport studies, Journal of Pharmaceutical Sciences, 100 (2011) 59-74.

[61] C.-T. Ho, R.-Z. Lin, W.-Y. Chang, H.-Y. Chang, C.-H. Liu, Rapid heterogeneous liver-cell on-chip patterning via the enhanced field-induced dielectrophoresis trap, Lab on a Chip, 6 (2006) 724-734.

[62] A. Carraro, W.-M. Hsu, K. Kulig, W. Cheung, M. Miller, E. Weinberg, E. Swart, M. Kaazempur-Mofrad, J. Borenstein, J. Vacanti, C. Neville, In vitro analysis of a hepatic device with intrinsic microvascular-based channels, Biomedical Microdevices, 10 (2008) 795-805.

[63] P.J. Lee, P.J. Hung, L.P. Lee, An artificial liver sinusoid with a microfluidic endotheliallike barrier for primary hepatocyte culture, Biotechnology and Bioengineering, 97 (2007) 13401346.

[64] S.R. Khetani, S.N. Bhatia, Microscale culture of human liver cells for drug development, Nature Biotechnology, 26 (2008) 120-126.

[65] D.C. Leslie, K. Domansky, G.A. Hamilton, A. Bahinski, D.E. Ingber, Aerosol drug delivery for lung on a chip, 15th International Conference on Miniaturized Systems for Chemistry and Life Sciences, (2011) 97-99.

[66] D. Huh, H. Fujioka, Y.-C. Tung, N. Futai, R. Paine, J.B. Grotberg, S. Takayama, Acoustically detectable cellular-level lung injury induced by fluid mechanical stresses in microfluidic airway systems, Proceedings of the National Academy of Sciences, 104 (2007) 18886-18891.

[67] K.-J. Jang, K.-Y. Suh, A multi-layer microfluidic device for efficient culture and analysis of renal tubular cells, Lab on a Chip, 10 (2010) 36-42.

[68] R. Baudoin, L. Griscom, M. Monge, C. Legallais, E. Leclerc, Development of a Renal Microchip for In Vitro Distal Tubule Models, Biotechnology Progress, 23 (2007) 1245-1253.

[69] H. Kimura, T. Yamamoto, H. Sakai, Y. Sakai, T. Fujii, An integrated microfluidic system for long-term perfusion culture and on-line monitoring of intestinal tissue models, Lab on a Chip, 8 (2008) 741-746.

[70] G.J. Mahler, M.B. Esch, R.P. Glahn, M.L. Shuler, Characterization of a gastrointestinal tract microscale cell culture analog used to predict drug toxicity, Biotechnology and Bioengineering, 104 (2009) 193-205.

[71] H.J. Kim, D. Huh, G. Hamilton, D.E. Ingber, Human gut-on-a-chip inhabited by microbial flora that experiences intestinal peristalsis-like motions and flow, Lab on a Chip, 12 (2012) 2165-2174.

[72] C. Franco, H. Gerhardt, Tissue engineering: Blood vessels on a chip, Nature, 488 (2012) 465-466.

[73] M. Shin, K. Matsuda, O. Ishii, H. Terai, M. Kaazempur-Mofrad, J. Borenstein, M. Detmar, J.P. Vacanti, Endothelialized networks with a vascular geometry in microfabricated poly (dimethyl siloxane), Biomedical Microdevices, 6 (2004) 269-278.

[74] J.W. Song, W. Gu, N. Futai, K.A. Warner, E. Jacques, S. Takayama, Computer-controlled microcirculatory support system for endothelial cell culture and shearing, Analytical Chemistry, 77 (2005) 3993-3999.

[75] A. Van Der Meer, A. Poot, M. Duits, J. Feijen, I. Vermes, Microfluidic technology in vascular research, Journal of biomedicine and biotechnology, 2009 (2009). 
[76] Y. Zheng, J. Chen, M. Craven, N.W. Choi, S. Totorica, A. Diaz-Santana, P. Kermani, B. Hempstead, C. Fischbach-Teschl, J.A. López, In vitro microvessels for the study of angiogenesis and thrombosis, Proceedings of the National Academy of Sciences, 109 (2012) 9342-9347.

[77] R.M. Nerem, A.E. Ensley, The tissue engineering of blood vessels and the heart, American Journal of Transplantation, 4 (2004) 36-42.

[78] P. Carmeliet, Angiogenesis in life, disease and medicine, Nature, 438 (2005) 932-936.

[79] M. Toner, D. Irimia, Blood-on-a-chip, Annu. Rev. Biomed. Eng., 7 (2005) 77-103.

[80] M.T. Lam, Y.-C. Huang, R.K. Birla, S. Takayama, Microfeature guided skeletal muscle tissue engineering for highly organized 3-dimensional free-standing constructs, Biomaterials, 30 (2009) 1150-1155.

[81] Y.-S. Torisawa, C.S. Spina, J.J. Collins, D.E. Ingber, Bone marrow-on-a-chip, in: 16th International Conference on Miniaturized Systems for Chemistry and Life Sciences, Okinawa, Japan, 2012.

[82] D. Wlodkowic, J.M. Cooper, Tumors on chips: oncology meets microfluidics, Current Opinion in Chemical Biology, 14 (2010) 556-567.

[83] J.P. Rolland, B.W. Maynor, L.E. Euliss, A.E. Exner, G.M. Denison, J.M. DeSimone, Direct Fabrication and Harvesting of Monodisperse, Shape-Specific Nanobiomaterials, Journal of the American Chemical Society, 127 (2005) 10096-10100.

[84] C. Park, J. Kim, S. Jang, H.G. Woo, Y.C. Ko, H. Sohn, Smart Particles for Noble Drug Delivery System, Journal of Nanoscience and Nanotechnology, 10 (2010) 3375-3379.

[85] I. Roy, M.N. Gupta, Smart Polymeric Materials: Emerging Biochemical Applications, Chemistry \&amp; Biology, 10 (2003) 1161-1171.

[86] R. Langer, D.A. Tirrell, Designing materials for biology and medicine, Nature, 428 (2004) 487-492.

[87] O.C. Farokhzad, S. Jon, A. Khademhosseini, T.-N.T. Tran, D.A. LaVan, R. Langer, Nanoparticle-Aptamer Bioconjugates, Cancer Research, 64 (2004) 7668-7672.

[88] S.L. Tao, T.A. Desai, Microfabricated drug delivery systems: from particles to pores, Advanced Drug Delivery Reviews, 55 (2003) 315-328.

[89] T.A. Desai, W.H. Chu, J.K. Tu, G.M. Beattie, A. Hayek, M. Ferrari, Microfabricated immunoisolating biocapsules, Biotechnology and Bioengineering, 57 (1998) 118-120.

[90] K.M. Ainslie, T.A. Desai, Microfabricated implants for applications in therapeutic delivery, tissue engineering, and biosensing, Lab on a Chip, 8 (2008) 1864-1878.

[91] D. Peer, J.M. Karp, S. Hong, O.C. Farokhzad, R. Margalit, R. Langer, Nanocarriers as an emerging platform for cancer therapy, Nat Nano, 2 (2007) 751-760.

[92] L. Leoni, T.A. Desai, Micromachined biocapsules for cell-based sensing and delivery, Advanced Drug Delivery Reviews, 56 (2004) 211-229.

[93] F.J. Martin, C. Grove, Microfabricated drug delivery systems: concepts to improve clinical benefit, Biomedical Microdevices, 3 (2001) 97-108.

[94] R.P. Lanza, J.L. Hayes, W.L. Chick, Encapsulated cell technology, Nature Biotechnology, 14 (1996) 1107-1111.

[95] P. de Vos, M.M. Faas, B. Strand, R. Calafiore, Alginate-based microcapsules for immunoisolation of pancreatic islets, Biomaterials, 27 (2006) 5603-5617.

[96] S. Kizilel, A. Scavone, X. Liu, J.M. Nothias, D. Ostrega, P. Witkowski, M. Millis, Encapsulation of pancreatic islets within nano-thin functional polyethylene glycol coatings for enhanced insulin secretion, Tissue Engineering Part A, 16 (2010) 2217-2228.

[97] N. Krishnamurthy, B. Gimi, Encapsulated cell grafts to treat cellular deficiencies and dysfunction, Critical reviews in biomedical engineering, 39 (2011) 473.

[98] A.D. Bangham, R.W. Horne, Action of Saponin on Biological Cell Membranes, Nature, 196 (1962) 952-953.

[99] V.P. Torchilin, Multifunctional nanocarriers, Advanced Drug Delivery Reviews. 
[100] A.L. Klibanov, K. Maruyama, V.P. Torchilin, L. Huang, Amphipathic polyethyleneglycols effectively prolong the circulation time of liposomes, FEBS Letters, 268 (1990) 235-237.

[101] G. Birnbaumer, S. Kupcu, C. Jungreuthmayer, L. Richter, K. Vorauer-Uhl, A. Wagner, C. Valenta, U. Sleytr, P. Ertl, Rapid liposome quality assessment using a lab-on-a-chip, Lab on a Chip, 11 (2011) 2753-2762.

[102] W.F. Daamen, P.J. Geutjes, H.T.B. van Moerkerk, S.T.M. Nillesen, R.G. Wismans, T. Hafmans, L.P.W.J. van den Heuvel, A.M.A. Pistorius, J.H. Veerkamp, J.C.M. van Hest, T.H. van Kuppevelt, "Lyophilisomes": A New Type of (Bio)capsule, Advanced Materials, 19 (2007) 673-677.

[103] v.B. Etienne, R. Raavé, W.P.R. Verdurmen, R.G. Wismans, P.J. Geutjes, R.E. Brock, E. Oosterwijk, T.H. van Kuppevelt, W.F. Daamen, Lyophilisomes as a new generation of drug delivery capsules, International Journal of Pharmaceutics, 439 (2012) 127-135.

[104] B.M. Discher, Y.-Y. Won, D.S. Ege, J.C.-M. Lee, F.S. Bates, D.E. Discher, D.A. Hammer, Polymersomes: Tough Vesicles Made from Diblock Copolymers, Science, 284 (1999) 11431146.

[105] Y. Wang, S.M. Grayson, Approaches for the preparation of non-linear amphiphilic polymers and their applications to drug delivery, Advanced Drug Delivery Reviews, 64 (2012) 852-865.

[106] M.-H. Li, P. Keller, Stimuli-responsive polymer vesicles, Soft Matter, 5 (2009) 927-937.

[107] J.A. Champion, Y.K. Katare, S. Mitragotri, Particle shape: a new design parameter for micro-and nanoscale drug delivery carriers, Journal of Controlled Release, 121 (2007) 3-9.

[108] J. Ko, H. Park, S. Hwang, J. Park, J. Lee, Preparation and characterization of chitosan microparticles intended for controlled drug delivery, International Journal of Pharmaceutics, 249 (2002) 165-174.

[109] G.M. Gelfuso, T. Gratieri, P.S. Simão, L.A.P. de Freitas, R.F.V. Lopez, Chitosan microparticles for sustaining the topical delivery of minoxidil sulphate, Journal of microencapsulation, 28 (2011) 650-658.

[110] T.A. Sonia, C. Sharma, Chitosan and Its Derivatives for Drug Delivery Perspective, in: R. Jayakumar, M. Prabaharan, R.A.A. Muzzarelli (Eds.) Chitosan for Biomaterials I, Springer Berlin Heidelberg, 2011, pp. 23-53.

[111] F.X. Gu, R. Karnik, A.Z. Wang, F. Alexis, E. Levy-Nissenbaum, S. Hong, R.S. Langer, O.C. Farokhzad, Targeted nanoparticles for cancer therapy, Nano Today, 2 (2007) 14-21.

[112] J. Panyam, V. Labhasetwar, Biodegradable nanoparticles for drug and gene delivery to cells and tissue, Advanced Drug Delivery Reviews, 64, Supplement (2012) 61-71.

[113] W.M. Pardridge, Drug delivery to the brain, Journal of Cerebral Blood Flow \& Metabolism, 17 (1997) 713-731.

[114] L. Serpe, Conventional Chemotherapeutic Drug Nanoparticles for Cancer Treatment, in: Nanotechnologies for the Life Sciences, Wiley-VCH Verlag GmbH \& Co. KGaA, 2007.

[115] C.E. Mora-Huertas, H. Fessi, A. Elaissari, Polymer-based nanocapsules for drug delivery, International Journal of Pharmaceutics, 385 (2010) 113-142.

[116] I. Brigger, C. Dubernet, P. Couvreur, Nanoparticles in cancer therapy and diagnosis, Advanced Drug Delivery Reviews, 64, Supplement (2012) 24-36.

[117] Z. Xiao, E. Levy-Nissenbaum, F. Alexis, A. Lupták, B.A. Teply, J.M. Chan, J. Shi, E. Digga, J. Cheng, R. Langer, O.C. Farokhzad, Engineering of Targeted Nanoparticles for Cancer Therapy Using Internalizing Aptamers Isolated by Cell-Uptake Selection, ACS Nano, 6 (2012) 696-704.

[118] Y. Chen, L. Liu, Modern methods for delivery of drugs across the blood-brain barrier, Advanced Drug Delivery Reviews, 64 (2012) 640-665. 
[119] E. Garcia-Garcia, K. Andrieux, S. Gil, P. Couvreur, Colloidal carriers and blood-brain barrier (BBB) translocation: A way to deliver drugs to the brain?, International Journal of Pharmaceutics, 298 (2005) 274-292.

[120] J. Kreuter, Nanoparticulate systems for brain delivery of drugs, Advanced Drug Delivery Reviews, 64, Supplement (2012) 213-222.

[121] B. Ziaie, A. Baldi, M. Lei, Y. Gu, R.A. Siegel, Hard and soft micromachining for BioMEMS: review of techniques and examples of applications in microfluidics and drug delivery, Advanced Drug Delivery Reviews, 56 (2004) 145-172.

[122] P. Tabeling, Introduction to microfluidics, Oxford University Press, USA, 2005.

[123] Y. Lu, S.C. Chen, Micro and nano-fabrication of biodegradable polymers for drug delivery, Advanced Drug Delivery Reviews, 56 (2004) 1621-1633.

[124] Y. Zhang, H.F. Chan, K.W. Leong, Advanced materials and processing for drug delivery: The past and the future, Advanced Drug Delivery Reviews, (2012).

[125] H. Iwata, N. Morikawa, T. Fujii, T. Takagi, T. Samejima, Y. Ikada, Does immunoisolation need to prevent the passage of antibodies and complements?, in: Transplantation proceedings, 1995, pp. 3224.

[126] G. Jeon, S.Y. Yang, J.K. Kim, Functional nanoporous membranes for drug delivery, Journal of Materials Chemistry, 22 (2012) 14814-14834.

[127] F. Martin, R. Walczak, A. Boiarski, M. Cohen, T. West, C. Cosentino, M. Ferrari, Tailoring width of microfabricated nanochannels to solute size can be used to control diffusion kinetics, Journal of Controlled Release, 102 (2005) 123-133.

[128] M.M. Deshmukh, D.C. Ralph, M. Thomas, J. Silcox, Nanofabrication using a stencil mask, Applied Physics Letters, 75 (1999) 1631-1633.

[129] J. Li, D. Stein, C. McMullan, D. Branton, M.J. Aziz, J.A. Golovchenko, Ion-beam sculpting at nanometre length scales, Nature, 412 (2001) 166-169.

[130] H.D. Tong, H.V. Jansen, V.J. Gadgil, C.G. Bostan, E. Berenschot, C.J.M. van Rijn, M. Elwenspoek, Silicon Nitride Nanosieve Membrane, Nano Letters, 4 (2004) 283-287.

[131] J.M. Macak, H. Tsuchiya, A. Ghicov, K. Yasuda, R. Hahn, S. Bauer, P. Schmuki, TiO2 nanotubes: Self-organized electrochemical formation, properties and applications, Current Opinion in Solid State and Materials Science, 11 (2007) 3-18.

[132] A. Ghicov, P. Schmuki, Self-ordering electrochemistry: a review on growth and functionality of $\mathrm{TiO} 2$ nanotubes and other self-aligned $\mathrm{MOx}$ structures, Chemical Communications, (2009) 2791-2808.

[133] S.Y. Yang, I. Ryu, H.Y. Kim, J.K. Kim, S.K. Jang, T.P. Russell, Nanoporous Membranes with Ultrahigh Selectivity and Flux for the Filtration of Viruses, Advanced Materials, 18 (2006) 709-712.

[134] J.K. Kim, S.Y. Yang, Y. Lee, Y. Kim, Functional nanomaterials based on block copolymer self-assembly, Progress in Polymer Science, 35 (2010) 1325-1349.

[135] U. Edlund, A.C. Albertsson, Degradable Polymer Microspheres for Controlled Drug Delivery, in: Degradable Aliphatic Polyesters, Springer Berlin Heidelberg, 2002, pp. 67-112.

[136] Q. Xu, M. Hashimoto, T.T. Dang, T. Hoare, D.S. Kohane, G.M. Whitesides, R. Langer, D.G. Anderson, Preparation of Monodisperse Biodegradable Polymer Microparticles Using a Microfluidic Flow-Focusing Device for Controlled Drug Delivery, Small, 5 (2009) 1575-1581.

[137] T.H. Lee, J. Wang, C.-H. Wang, Double-walled microspheres for the sustained release of a highly water soluble drug: characterization and irradiation studies, Journal of Controlled Release, 83 (2002) 437-452.

[138] W. Lee, E. Widjaja, S. Loo, Designing drug-loaded multi-layered polymeric microparticles, Journal of Materials Science: Materials in Medicine, 23 (2012) 81-88. 
[139] F.-Y. Hsu, D.-S. Yu, C.-C. Huang, Development of $\mathrm{pH}$-sensitive pectinate/alginate microspheres for colon drug delivery, Journal of Materials Science: Materials in Medicine, (2012) 1-7.

[140] S. De Koker, R. Hoogenboom, B.G. De Geest, Polymeric multilayer capsules for drug delivery, Chemical Society Reviews, 41 (2012) 2867-2884.

[141] P.M. Andres Garcia, Stuart Williams, et al.,, Microfabricated Engineered Particle Systems for Respiratory Drug Delivery and Other Pharmaceutical Applications, Journal of Drug Delivery, 2012 (2012).

[142] J. Pan, S.Y. Chan, W.G. Lee, L. Kang, Microfabricated particulate drug-delivery systems, Biotechnology Journal, 6 (2011) 1477-1487.

[143] D.A. Canelas, K.P. Herlihy, J.M. DeSimone, Top-down particle fabrication: control of size and shape for diagnostic imaging and drug delivery, Wiley Interdisciplinary Reviews: Nanomedicine and Nanobiotechnology, 1 (2009) 391-404.

[144] M. Wang, H.G. Braun, T. Kratzmüller, E. Meyer, Patterning Polymers by Micro-FluidContact Printing, Advanced Materials, 13 (2001) 1312-1317.

[145] X.-M. Zhao, Y. Xia, G.M. Whitesides, Fabrication of three-dimensional micro-structures: Microtransfer molding, Advanced Materials, 8 (1996) 837-840.

[146] D. Dendukuri, D.C. Pregibon, J. Collins, T.A. Hatton, P.S. Doyle, Continuous-flow lithography for high-throughput microparticle synthesis, Nat Mater, 5 (2006) 365-369.

[147] J. Guan, A. Chakrapani, D.J. Hansford, Polymer Microparticles Fabricated by Soft Lithography, Chemistry of Materials, 17 (2005) 6227-6229.

[148] S. Sant, S.L. Tao, O.Z. Fisher, Q. Xu, N.A. Peppas, A. Khademhosseini, Microfabrication technologies for oral drug delivery, Advanced Drug Delivery Reviews, 64 (2012) 496-507.

[149] L.C. Glangchai, M. Caldorera-Moore, L. Shi, K. Roy, Nanoimprint lithography based fabrication of shape-specific, enzymatically-triggered smart nanoparticles, Journal of Controlled Release, 125 (2008) 263-272.

[150] J.A. Champion, Y.K. Katare, S. Mitragotri, Particle shape: A new design parameter for micro- and nanoscale drug delivery carriers, Journal of Controlled Release, 121 (2007) 3-9.

[151] H.-K. Chan, P.C.L. Kwok, Production methods for nanodrug particles using the bottom-up approach, Advanced Drug Delivery Reviews, 63 (2011) 406-416.

[152] O. Veiseh, J.W. Gunn, M. Zhang, Design and fabrication of magnetic nanoparticles for targeted drug delivery and imaging, Advanced Drug Delivery Reviews, 62 (2010) 284-304.

[153] F. Danhier, E. Ansorena, J.M. Silva, R. Coco, A. Le Breton, V. Préat, PLGA-based nanoparticles: An overview of biomedical applications, Journal of Controlled Release, 161 (2012) 505-522.

[154] C.R. Patra, R. Bhattacharya, D. Mukhopadhyay, P. Mukherjee, Fabrication of gold nanoparticles for targeted therapy in pancreatic cancer, Advanced Drug Delivery Reviews, 62 (2010) 346-361.

[155] C. Roney, P. Kulkarni, V. Arora, P. Antich, F. Bonte, A. Wu, N.N. Mallikarjuana, S. Manohar, H.-F. Liang, A.R. Kulkarni, H.-W. Sung, M. Sairam, T.M. Aminabhavi, Targeted nanoparticles for drug delivery through the blood-brain barrier for Alzheimer's disease, Journal of Controlled Release, 108 (2005) 193-214.

[156] Y.-C. Kim, J.-H. Park, M.R. Prausnitz, Microneedles for drug and vaccine delivery, Advanced Drug Delivery Reviews.

[157] S. Henry, D.V. McAllister, M.G. Allen, M.R. Prausnitz, Microfabricated microneedles: A novel approach to transdermal drug delivery, Journal of Pharmaceutical Sciences, 87 (1998) 922-925.

[158] G. Yan, K.S. Warner, J. Zhang, S. Sharma, B.K. Gale, Evaluation needle length and density of microneedle arrays in the pretreatment of skin for transdermal drug delivery, International Journal of Pharmaceutics, 391 (2010) 7-12. 
[159] J. Ji, F.E.H. Tay, J. Miao, C. Iliescu, Microfabricated silicon microneedle array for transdermal drug delivery, Journal of Physics: Conference Series, 34 (2006) 1127-1131.

[160] N. Wilke, A. Mulcahy, S.R. Ye, A. Morrissey, Process optimization and characterization of silicon microneedles fabricated by wet etch technology, Microelectronics Journal, 36 (2005) 650-656.

[161] Y. Qiu, Y. Gao, K. Hu, F. Li, Enhancement of skin permeation of docetaxel: A novel approach combining microneedle and elastic liposomes, Journal of Controlled Release, 129 (2008) 144-150.

[162] L. Wei-Ze, H. Mei-Rong, Z. Jian-Ping, Z. Yong-Qiang, H. Bao-Hua, L. Ting, Z. Yong, Super-short solid silicon microneedles for transdermal drug delivery applications, International Journal of Pharmaceutics, 389 (2010) 122-129.

[163] Y.T. Chen, C.C. Hsu, C.H. Tsai, S.W. Kang, Fabrication of microneedles, Journal of Marine Science and Technology, 18 (2010) 243-248.

[164] T. Omatsu, K. Chujo, K. Miyamoto, M. Okida, K. Nakamura, N. Aoki, R. Morita, Metal microneedle fabrication using twisted light with spin, Optics Express, 18 (2010) 17967-17973.

[165] S.P. Davis, W. Martanto, M.G. Allen, M.R. Prausnitz, Hollow metal microneedles for insulin delivery to diabetic rats, IEEE Transactions on Biomedical Engineering, 52 (2005) 909915.

[166] J.H. Park, Y.K. Yoon, S.O. Choi, M.R. Prausnitz, M.G. Allen, Tapered conical polymer microneedles fabricated using an integrated lens technique for transdermal drug delivery, IEEE Transactions on Biomedical Engineering, 54 (2007) 903-913.

[167] K. Kim, D.S. Park, H.M. Lu, W. Che, J.B. Lee, C.H. Ahn, A tapered hollow metallic microneedle array using backside exposure of SU-8, Journal of Micromechanics and Microengineering, 14 (2004) 597-603.

[168] M. Han, D.H. Hyun, H.H. Park, S.S. Lee, C.H. Kim, C. Kim, A novel fabrication process for out-of-plane microneedle sheets of biocompatible polymer, Journal of Micromechanics and Microengineering, 17 (2007) 1184-1191.

[169] S.D. Gittard, A. Ovsianikov, N.A. Monteiro-Riviere, J. Lusk, P. Morel, P. Minghetti, C. Lenardi, B.N. Chichkov, R.J. Narayan, Fabrication of polymer microneedles using a two-photon polymerization and micromolding process, Journal of diabetes science and technology, 3 (2009) 304-311.

[170] K.-S. Lee, R.H. Kim, D.-Y. Yang, S.H. Park, Advances in 3D nano/microfabrication using two-photon initiated polymerization, Progress in Polymer Science, 33 (2008) 631-681.

[171] J.-H. Park, M.G. Allen, M.R. Prausnitz, Biodegradable polymer microneedles: Fabrication, mechanics and transdermal drug delivery, Journal of Controlled Release, 104 (2005) 51-66.

[172] S.J. Moon, S.S. Lee, A novel fabrication method of a microneedle array using inclined deep x-ray exposure, Journal of Micromechanics and Microengineering, 15 (2005) 903-911.

[173] S. Bystrova, R. Luttge, Micromolding for ceramic microneedle arrays, Microelectronic Engineering, 88 (2011) 1681-1684.

[174] A. Ovsianikov, B. Chichkov, P. Mente, N.A. Monteiro-Riviere, A. Doraiswamy, R.J. Narayan, Two photon polymerization of polymer-ceramic hybrid materials for transdermal drug delivery, International Journal of Applied Ceramic Technology, 4 (2007) 22-29.

[175] A. Doraiswamy, C. Jin, R.J. Narayan, P. Mageswaran, P. Mente, R. Modi, R. Auyeung, D.B. Chrisey, A. Ovsianikov, B. Chichkov, Two photon induced polymerization of organicinorganic hybrid biomaterials for microstructured medical devices, Acta Biomaterialia, 2 (2006) 267-275.

[176] S. Doddaballapur, Microneedling with dermaroller, J Cutan Aesthet Surg, 2 (2009) 110111. 
[177] J.W. So, H.H. Park, S.S. Lee, D.C. Kim, S.C. Shin, C.W. Cho, Effect of microneedle on the pharmacokinetics of ketoprofen from its transdermal formulations, Drug Delivery, 16 (2009) 52-56.

[178] C.P. Zhou, Y.L. Liu, H.L. Wang, P.X. Zhang, J.L. Zhang, Transdermal delivery of insulin using microneedle rollers in vivo, International Journal of Pharmaceutics, 392 (2010) 127-133.

[179] J.H. Park, S.O. Choi, S. Seo, Y.B. Choy, M.R. Prausnitz, A microneedle roller for transdermal drug delivery, European Journal of Pharmaceutics and Biopharmaceutics, 76 (2010) 282-289.

[180] N. Roxhed, T.C. Gasser, P. Griss, G.A. Holzapfel, G. Stemme, Penetration-enhanced ultrasharp microneedles and prediction on skin interaction for efficient transdermal drug delivery, Microelectromechanical Systems, Journal of, 16 (2007) 1429-1440.

[181] H.J.G.E. Gardeniers, R. Luttge, E.J.W. Berenschot, M.J. De Boer, S.Y. Yeshurun, M. Hefetz, R. van't Oever, A. van den Berg, Silicon micromachined hollow microneedles for transdermal liquid transport, Microelectromechanical Systems, Journal of, 12 (2003) 855-862.

[182] R. Luttge, E.J.W. Berenschot, M.J. de Boer, D.M. Altpeter, E.X. Vrouwe, A. van den Berg, M. Elwenspoek, Integrated lithographic molding for microneedle-based devices, Microelectromechanical Systems, Journal of, 16 (2007) 872-884.

[183] F. Perennes, B. Marmiroli, M. Matteucci, M. Tormen, L. Vaccari, E. Di Fabrizio, Sharp beveled tip hollow microneedle arrays fabricated by LIGA and 3D soft lithography with polyvinyl alcohol, Journal of Micromechanics and Microengineering, 16 (2006) 473.

[184] B. Ma, S. Liu, Z. Gan, G. Liu, X. Cai, H. Zhang, Z. Yang, A PZT insulin pump integrated with a silicon microneedle array for transdermal drug delivery, Microfluidics and Nanofluidics, 2 (2006) 417-423.

[185] L. Yu, F. Tay, D. Guo, L. Xu, K. Yap, A microfabricated electrode with hollow microneedles for ECG measurement, Sensors and Actuators A: Physical, 151 (2009) 17-22.

[186] N. Wilke, C. Hibert, J. O’Brien, A. Morrissey, Silicon microneedle electrode array with temperature monitoring for electroporation, Sensors and Actuators A: Physical, 123 (2005) 319325.

[187] E. Mukerjee, S. Collins, R. Isseroff, R. Smith, Microneedle array for transdermal biological fluid extraction and in situ analysis, Sensors and Actuators A: Physical, 114 (2004) 267-275.

[188] P.M. Wang, M. Cornwell, J. Hill, M.R. Prausnitz, Precise microinjection into skin using hollow microneedles, Journal of investigative dermatology, 126 (2006) 1080-1087.

[189] L. Daugimont, N. Baron, G. Vandermeulen, N. Pavselj, D. Miklavcic, M.C. Jullien, G. Cabodevila, L.M. Mir, V. Préat, Hollow microneedle arrays for intradermal drug delivery and DNA electroporation, Journal of Membrane Biology, 236 (2010) 117-125.

[190] U.O. Häfeli, A. Mokhtari, D. Liepmann, B. Stoeber, In vivo evaluation of a microneedlebased miniature syringe for intradermal drug delivery, Biomedical microdevices, 11 (2009) 943950.

[191] W. Martanto, J.S. Moore, O. Kashlan, R. Kamath, P.M. Wang, J.M. O'Neal, M.R. Prausnitz, Microinfusion using hollow microneedles, Pharmaceutical Research, 23 (2006) 104113.

[192] S.A. Burton, C.Y. Ng, R. Simmers, C. Moeckly, D. Brandwein, T. Gilbert, N. Johnson, K. Brown, T. Alston, G. Prochnow, Rapid intradermal delivery of liquid formulations using a hollow microstructured array, Pharmaceutical Research, 28 (2011) 31-40.

[193] W.G. Ali, G. Nagib, Embedded Control Design for Insulin Pump, Advanced Materials Research, 201 (2011) 2399-2404.

[194] F. Amirouche, Y. Zhou, T. Johnson, Current micropump technologies and their biomedical applications, Microsystem Technologies, 15 (2009) 647-666. 
[195] M. Ashraf, S. Tayyaba, A. Nisar, N. Afzulpurkar, D. Bodhale, T. Lomas, A. Poyai, A. Tuantranont, Design, fabrication and analysis of silicon hollow microneedles for transdermal drug delivery system for treatment of hemodynamic dysfunctions, Cardiovascular Engineering, 10 (2010) 91-108.

[196] N. Wonglertnirant, H. Todo, P. Opanasopit, T. Ngawhirunpat, K. Sugibayashi, Macromolecular delivery into skin using a hollow microneedle, Biological and Pharmaceutical Bulletin, 33 (2010) 1988-1993.

[197] H.S. Gill, M.R. Prausnitz, Coated microneedles for transdermal delivery, Journal of Controlled Release, 117 (2007) 227-237.

[198] H.S. Gill, M.R. Prausnitz, Coating formulations for microneedles, Pharmaceutical Research, 24 (2007) 1369-1380.

[199] R. Stokes, D. Evans, M. Errico, Liquid coating processes, Fundamentals of Interfacial Engineering, Wiley-VCH, Weinheim, Germany, (1997) 399-456.

[200] M. Ameri, S.C. Fan, Y.F. Maa, Parathyroid hormone PTH(1-34) formulation that enables uniform coating on a novel transdermal microprojection delivery system, Pharmaceutical Research, 27 (2010) 303-313.

[201] E.M. Saurer, R.M. Flessner, S.P. Sullivan, M.R. Prausnitz, D.M. Lynn, Layer-by-layer assembly of DNA- and protein-containing films on microneedles for drug delivery to the skin, Biomacromolecules, 11 (2010) 3136-3143.

[202] M.G. McGrath, A. Vrdoljak, C. O’Mahony, J.C. Oliveira, A.C. Moore, A.M. Crean, Determination of parameters for successful spray coating of silicon microneedle arrays, International Journal of Pharmaceutics, 415 (2011) 140-149.

[203] M. Cormier, B. Johnson, M. Ameri, K. Nyam, L. Libiran, D.D. Zhang, P. Daddona, Transdermal delivery of desmopressin using a coated microneedle array patch system, Journal of Controlled Release, 97 (2004) 503-511.

[204] X. Chen, T.W. Prow, M.L. Crichton, D.W.K. Jenkins, M.S. Roberts, I.H. Frazer, G.J.P. Fernando, M.A.F. Kendall, Dry-coated microprojection array patches for targeted delivery of immunotherapeutics to the skin, Journal of Controlled Release, 139 (2009) 212-220.

[205] H.S. Gill, M.R. Prausnitz, Pocketed microneedles for drug delivery to the skin, Journal of Physics and Chemistry of Solids, 69 (2008) 1537-1541.

[206] Y.C. Kim, F.S. Quan, R.W. Compans, S.M. Kang, M.R. Prausnitz, Formulation and coating of microneedles with inactivated influenza virus to improve vaccine stability and immunogenicity, Journal of Controlled Release, 142 (2010) 187-195.

[207] E.M. Saurer, R.M. Flessner, S.P. Sullivan, M.R. Prausnitz, D.M. Lynn, Layer-by-layer assembly of DNA-and protein-containing films on microneedles for drug delivery to the skin, Biomacromolecules, (2010).

[208] K. Fukushima, A. Ise, H. Morita, R. Hasegawa, Y. Ito, N. Sugioka, K. Takada, Twolayered dissolving microneedles for percutaneous delivery of peptide/protein drugs in rats, Pharmaceutical Research, 28 (2011) 7-21.

[209] L.Y. Chu, M.R. Prausnitz, Separable arrowhead microneedles, Journal of Controlled Release, 149 (2011) 242-249.

[210] J.H. Park, M.G. Allen, M.R. Prausnitz, Polymer microneedles for controlled-release drug delivery, Pharmaceutical Research, 23 (2006) 1008-1019.

[211] M.Y. Kim, B. Jung, J.H. Park, Hydrogel swelling as a trigger to release biodegradable polymer microneedles in skin, Biomaterials, (2011).

[212] J.H. Park, S.O. Choi, R. Kamath, Y.K. Yoon, M.G. Allen, M.R. Prausnitz, Polymer particle-based micromolding to fabricate novel microstructures, Biomedical microdevices, 9 (2007) 223-234. 
[213] L.Y. Chu, S.O. Choi, M.R. Prausnitz, Fabrication of dissolving polymer microneedles for controlled drug encapsulation and delivery: Bubble and pedestal microneedle designs, Journal of Pharmaceutical Sciences, 99 (2010) 4228-4238.

[214] M. Baker, A living system on a chip, Nature, 471 (2011) 661-665.

[215] A. Gunther, S. Yasotharan, A. Vagaon, C. Lochovsky, S. Pinto, J. Yang, C. Lau, J. Voigtlaender-Bolz, S.-S. Bolz, A microfluidic platform for probing small artery structure and function, Lab on a Chip, 10 (2010) 2341-2349.

[216] P.M. van Midwoud, E. Verpoorte, G.M.M. Groothuis, Microfluidic devices for in vitro studies on liver drug metabolism and toxicity, Integrative Biology, 3 (2011) 509-521.

[217] C. Moraes, G. Mehta, S. Lesher-Perez, S. Takayama, Organs-on-a-Chip: A Focus on Compartmentalized Microdevices, Annals of Biomedical Engineering, 40 (2012) 1211-1227.

[218] Y. Wang, R. Dhopeshwarkar, R. Najdi, M.L. Waterman, C.E. Sims, N. Allbritton, Microdevice to capture colon crypts for in vitro studies, Lab on a Chip, 10 (2010) 1596-1603.

[219] D.R. Albrecht, G.H. Underhill, T.B. Wassermann, R.L. Sah, S.N. Bhatia, Probing the role of multicellular organization in three-dimensional microenvironments, Nat Meth, 3 (2006) 369375.

[220] M.B. Esch, T.L. King, M.L. Shuler, The Role of Body-on-a-Chip Devices in Drug and Toxicity Studies, Annual Review of Biomedical Engineering, 13 (2011) 55-72.

[221] J.H. Sung, C. Kam, M.L. Shuler, A microfluidic device for a pharmacokineticpharmacodynamic (PK-PD) model on a chip, Lab on a Chip, 10 (2010) 446-455.

[222] J.H. Sung, M.L. Shuler, A micro cell culture analog ([small micro]CCA) with 3-D hydrogel culture of multiple cell lines to assess metabolism-dependent cytotoxicity of anticancer drugs, Lab on a Chip, 9 (2009) 1385-1394.

[223] J.J.T. Santini, A.C. Richards, R. Scheidt, M.J. Cima, R. Langer, Microchips as Controlled Drug-Delivery Devices, Angewandte Chemie International Edition, 39 (2000) 2396-2407.

[224] A.J. Chung, D. Kim, D. Erickson, Electrokinetic microfluidic devices for rapid, low power drug delivery in autonomous microsystems, Lab on a Chip, 8 (2008) 330-338.

[225] C.E. Krewson, W.M. Saltzman, Transport and elimination of recombinant human NGF during long-term delivery to the brain, Brain Research, 727 (1996) 169-181.

[226] C. Foley, N. Nishimura, K. Neeves, C. Schaffer, W. Olbricht, Flexible microfluidic devices supported by biodegradable insertion scaffolds for convection-enhanced neural drug delivery, Biomedical Microdevices, 11 (2009) 915-924.

[227] G.W. Astary, S. Kantorovich, P.R. Carney, T.H. Mareci, M. Sarntinoranont, Regional convection-enhanced delivery of gadolinium-labeled albumin in the rat hippocampus in vivo, Journal of Neuroscience Methods, 187 (2010) 129-137.

[228] K.B. Neeves, C.T. Lo, C.P. Foley, W.M. Saltzman, W.L. Olbricht, Fabrication and characterization of microfluidic probes for convection enhanced drug delivery, Journal of Controlled Release, 111 (2006) 252-262.

[229] R. Lo, P.-Y. Li, S. Saati, R. Agrawal, M. Humayun, E. Meng, A passive MEMS drug delivery pump for treatment of ocular diseases, Biomedical Microdevices, 11 (2009) 959-970.

[230] P.-Y. Li, J. Shih, R. Lo, S. Saati, R. Agrawal, M.S. Humayun, Y.-C. Tai, E. Meng, An electrochemical intraocular drug delivery device, Sensors and Actuators A: Physical, 143 (2008) 41-48.

[231] H. Gensler, R. Sheybani, P.-Y. Li, R. Mann, E. Meng, An implantable MEMS micropump system for drug delivery in small animals, Biomedical Microdevices, 14 (2012) 483-496.

[232] F.N. Pirmoradi, J.K. Jackson, H.M. Burt, M. Chiao, On-demand controlled release of docetaxel from a battery-less MEMS drug delivery device, Lab on a Chip, 11 (2011) 2744-2752. [233] N.M. Elman, H.L. Ho Duc, M.J. Cima, An implantable MEMS drug delivery device for rapid delivery in ambulatory emergency care, Biomedical Microdevices, 11 (2009) 625-631. 
[234] P. Rohatgi, N.B. Langhals, D.R. Kipke, P.G. Patil, In vivo performance of a microelectrode neural probe with integrated drug delivery, Neurosurgical Focus, 27 (2009) E8. [235] S.T. Retterer, K.L. Smith, C.S. Bjornsson, J.N. Turner, M.S. Isaacson, W. Shain, Constant pressure fluid infusion into rat neocortex from implantable microfluidic devices, Journal of Neural Engineering, 5 (2008) 385.

[236] D.P. Papageorgiou, S.E. Shore, S.C. Bledsoe, K.D. Wise, A shuttered neural probe with on-chip flowmeters for chronic in vivo drug delivery, Microelectromechanical Systems, Journal of, 15 (2006) 1025-1033.

[237] A. Altuna, E. Bellistri, E. Cid, P. Aivar, B. Gal, J. Berganzo, G. Gabriel, A. Guimera, R. Villa, L.J. Fernandez, L. Menendez de la Prida, SU-8 based microprobes for simultaneous neural depth recording and drug delivery in the brain, Lab on a Chip, (2013).

[238] E.E.L. Pararas, Z. Chen, J. Fiering, M.J. Mescher, E.S. Kim, M.J. McKenna, S.G. Kujawa, J.T. Borenstein, W.F. Sewell, Kinetics of reciprocating drug delivery to the inner ear, Journal of Controlled Release, 152 (2011) 270-277.

[239] J.T. Borenstein, Intracochlear drug delivery systems, Expert Opinion on Drug Delivery, 8 (2011) 1161-1174.

[240] W.F. Sewell, J.T. Borenstein, Z. Chen, J. Fiering, O. Handzel, M. Holmboe, E.S. Kim, S.G. Kujawa, M.J. McKenna, M.M. Mescher, B. Murphy, E.E.L. Swan, M. Peppi, S. Tao, Development of a Microfluidics-Based Intracochlear Drug Delivery Device, Audiology and Neuro-Otology, 14 (2009) 411-422. 